\title{
Savings in classical conditioning in the rabbit as a function of extended extinction
}

\author{
GABRIELLE WEIDEMANN and E. JAMES KEHOE \\ University of New South Wales, Sydney, Australia
}

\begin{abstract}
In the present experiments, savings phenomena following a limited amount of initial acquisition and extended extinction were examined. Experiments 1 and 2 compared rates of reacquisition following brief acquisition and various amounts of extinction in conditioning of the rabbit's nictitating membrane and heart rate response, respectively. Experiment 3 compared rates of acquisition to a novel stimulus (e.g., light) following brief acquisition and various amounts of extinction to another stimulus (e.g., tone). In addition, in Experiment 3 recovery of responding to the extinguished stimulus during acquisition to the novel, cross-modal stimulus was examined. Experiments 1, 2, and 3 demonstrated that with a limited number of acquisition trials (1) there was a graded reduction in the rate of reacquisition as a function of the number of extinction trials in both conditioning preparations, (2) there was a graded reduction in the rate of cross-modal acquisition as a function of the number of extinction trials, but (3), in Experiment 3, recovery of responding to the extinguished stimulus during cross-modal training of the novel stimulus appeared uniformly robust even in the face of extended extinction.
\end{abstract}

Nonreinforced presentations of a previously reinforced conditioned stimulus (CS) produces a progressive elimination of the conditioned response (CR) known as extinction. Superficially, this elimination of behavior appears to be the reverse of original learning. However, even after complete elimination of a CR, a substantial residual of the original learning is saved and, as will be detailed below, can be readily demonstrated in a variety of ways. Practically, extinctionis the foundation for exposure-based therapies (Bouton \& Nelson, 1998; Kehoe \& Macrae, 1997; W. R. McAllister \& D. E. McAllister, 1995). Such therapies can be highly successful, but, like laboratory extinction, savings are commonly seen in the form of high rates of relapse (Marlatt, 1990; Shiffman, Paty, Gnys, Kassel, \& Hickcox, 1996). Hence, understanding savings after extinction has widespread significance for basic theories of conditioning and for their applications.

Previous studies using the rabbit nictitating membrane (NM) preparation have shown three forms of savings after extinction of the CR. The first form is rapid reacquisition: When the original CS is again paired with the unconditioned stimulus (US), reacquisition of the CR is more rapid than acquisition in a naive control group (Macrae \& Kehoe, 1999; Napier, Macrae, \& Kehoe, 1992; Smith \& Gormezano, 1965). The second form of savings occurs in cross-modal acquisition (CMA): When a new CS from a different modality is introduced after extinc-

Preparation of this manuscript was supported by Australian Research Council Grant A79917018. Correspondence should be sent to E. J. Kehoe, School of Psychology, University of New South Wales, Sydney, NSW 2052, Australia (e-mail: jkehoe@ unsw.edu.au).

Accepted by previous editorial team of Ralph R. Miller. tion, $\mathrm{CR}$ acquisition to the new $\mathrm{CS}$ is more rapid than it is in a naive control group (Kehoe, Morrow, \& Holt, 1984; Macrae \& Kehoe, 1999). The third form of savings is concurrent recovery, which occurs during CMA: When the original CS is tested, CRs to the original CS recover up to $75 \%$ of their original likelihood, despite the fact that the original CS has not been reinforced since initial acquisition training (Kehoe, Horne, \& Macrae, 1995; Macrae \& Kehoe, 1999).

Although savings in the rabbit NM preparation are robust, a review of findings in studies using rats reveals that the size and direction of savings are variable, even within the same response system. In taste-aversion learning in rats, rapid reacquisition has been observed (Revusky \& Coombes, 1979), but "slow reacquisition" has been more common (Aguado, de Brugada, \& Hall, 2001; Calton, Mitchell, \& Schachtman, 1996; Hart, Bourne, \& Schachtman, 1995). For example, Hart et al. (1995) found that reacquisition was retarded relative to a "learningexperienced" control group that had received training and extinction with an orthogonal taste, for which there was little, if any, stimulus generalization. Similarly, in studies of conditioned fear in rats, rapid reacquisition has occurred in an escape-from-fear task (D. E. McAllister \& W. R. McAllister, 1994). However, in conditioned suppression, reacquisition has been retarded, particularly when extinction was extended from 24 trials to 72 trials (Bouton, 1986).

Comparing across experiments from different laboratories makes it difficult to identify which variables control the variation in the appearance of savings after extinction. Recently, however, Ricker and Bouton (1996) have reported a series of appetitive conditioning experiments in which the results suggest that decreasing the amount of acquisition training and/or increasing the amount of 
extinction training can convert rapid reacquisition into retarded reacquisition. Specifically, Ricker and Bouton (1996, Experiment 1A) found that, when rats were given 45 acquisition trials and 80 extinction trials, subsequent reacquisition was rapid. Conversely, when rats were given only 8 acquisition trials and 88 extinction trials, subsequent reacquisition was slow in comparison with that of both a naive control group and a learning-experienced group (Ricker \& Bouton, 1996, Experiment 4).

In rabbit eyelid conditioning, reacquisition has usually been rapid following substantial acquisition training and moderate to extended extinction training. For example, Napier et al. (1992) gave their animals 180 initial CS-US pairings followed by either $300 \mathrm{CS}$-alone trials (Experiment 1) or $900 \mathrm{CS}$-alone trials (Experiment 3). In both cases, reacquisition was rapid relative to a naive control group. Similarly, Medina, Garcia, and Mauk (2001) compared different amounts of extinction within the same experiment. They gave their rabbits 480 initial CS-US pairings followed by $540,1,620$, or 4,860 CS-alone trials. The rate of reacquisition diminished as the number of extinction trials was increased. However, in their case, one cannot be sure whether reacquisition at the most extended extinction was rapid, retarded, or neither. A betweengroups comparison was not possible because there was no naive control group. A within-groups comparison would not be entirely safe, because the rabbits were tested for responding to the CS before initial training, which might have reduced the rate of initial acquisition.

The findings concerning cross-modal savings after extinction are sparse. Westbrook and Homewood (1982, Experiment 6) found that taste-aversion learning with one flavor (e.g., salt) facilitated the rate of learning with a new, orthogonal flavor (e.g., sucrose). If, however, the original aversion was extinguished, the facilitation of learning failed to appear. In contrast, in rabbit eyelid conditioning, cross-modal savings consistently survive moderate extinction (Kehoe et al., 1984; Macrae \& Kehoe, 1999) after substantial acquisition training.

The empirical aim of the present experiments was to delineate more clearly the effect of different amounts of extinction after a small amount of initial acquisition training. These experiments stem particularly from Ricker and Bouton's (1996) conclusion that brief acquisition training followed by massive extinction should result in retarded reacquisition (see also Aguado et al., 2001; Calton et al., 1996; Hart et al., 1995). Accordingly, we examined reacquisition in two different response systems in the rabbit-namely, the NM response (Experiment 1) and the heart rate (HR) response (Experiment 2). We also examined cross-modal savings in the NM response system after brief initial training and different amounts of extinction (Experiment 3).

The design of the present experiments was intended to make two advances on previous designs. First, with the exception of one of Ricker and Bouton's (1996) experiments, other studies of savings have used enough initial training trials to establish the CR at a high level. In the present experiments, we used just enough trials to pro- duce conditioned responding that was about half of its asymptotic level. Second, maximum ratios of 9-11 CS extinction trials for each initial CS-US pairing have been used in previous studies (Hart et al., 1995; Medina et al., 2001; Ricker \& Bouton, 1996). In the present experiments, we used a maximum ratio of 26 extinction trials for each initial acquisition trial in the two NM experiments, and for HR conditioning, we used a maximum ratio of 20 extinction trials to each acquisition trial.

\section{EXPERIMENT 1}

In Experiment 1, we examined reacquisition following brief acquisition and various amounts of extinction in the rabbit NM preparation. The reacquisition groups received 45 CS-US acquisition trials followed by 300,600 , or 1,200 CS-alone extinction trials. Finally, all groups received reacquisition (RAQ) training. These groups were designated RAQ-300, RAQ-600, and RAQ-1,200, according to the number of extinction trials they received. In all three reacquisition groups, the number of days (20) between the end of initial acquisition training and the beginning of reacquisition training was held constant so as not to confound the amount of extinction with the length of the retention interval. According to findings by Schreurs $(1993,1998)$, the total retention interval of 20 days was far too short to produce a detectable loss of responding; retention intervals longer than 6 months would be required.

The experiment also included a naive acquisition group, designated as Group Rest. This group received exposure to the apparatus for the first two stages of training and then, along with the reacquisition groups, received CS-US pairings in the final stage of training. A rest control group that was exposed to the apparatus was used for methodological and theoretical reasons. Methodologically, the control group had the same apparatus exposure as the reacquisition groups had. There is evidence that prior exposure to apparatus cues has a paradoxical effect; specifically, latent inhibition of the apparatus cues facilitates acquisition when pairings of a discrete CS with the US are introduced (Grant \& Young, 1971; Hinson, 1982; Maes \& Vossen, 1993). Hence, the use of apparatus exposure may set a high baseline, making it more difficult to detect rapid reacquisition but easier to detect retarded reacquisition. As a counterweight to any bias in Group Rest, we also analyzed the rate of initial acquisition in Stage 1 as a within-subjects comparison to assess the relative rate of reacquisition to naive acquisition without prior apparatus exposure.

\section{Method}

\section{Subjects}

The subjects were 32 experimentally naive female, albino rabbits (Oryctolagus cuniculus). On arrival from the university's breeding unit, they were 70-80 days old and weighed approximately $1.5 \mathrm{~kg}$ each. All the rabbits were individually housed and had free access to food and water.

\footnotetext{
Apparatus

The apparatus and recording procedures for the NM response
} were modeled after those described by Gormezano (1966). During 
training, each subject was restrained in a Perspex box $(45 \times 14 \times$ $12 \mathrm{~cm}$ ). The rabbit was held in place by insertion of its head through an adjustable stock and by securing its ears to the front of the stock with a polyurethane foam-covered metal clamp. The rabbits were trained individually in one of eight sound-attenuating chambers. In each chamber, a speaker was mounted approximately $8 \mathrm{~cm}$ anterior to and $16 \mathrm{~cm}$ above the subject's head. The speaker delivered the auditory CS, which was a $1000-\mathrm{Hz}, 94-\mathrm{dB}$ (SPL) tone of 250-msec duration, superimposed on an ambient noise level of $81 \mathrm{~dB}$ provided by exhaust fans. A 94-dB tone was used in order for the CS to be clearly distinguishable from the background noise and to establish reliable levels of responding within a relatively small number of trials (Kehoe, 2000; Scavio \& Gormezano, 1974). An 8-W neon houselight was mounted $4 \mathrm{~cm}$ above the speaker. The US was a 50-msec, 3-mA, 50-Hz AC electric current delivered via 9-mm stainless steel Autoclip wound clips positioned $10 \mathrm{~mm}$ apart and $15 \mathrm{~mm}$ posterior to the dorsal canthus of the rabbit's right eye. Additional wound clips were applied during the experiment when necessary. The sequence and timing of stimulus events were controlled by an Apple II computer equipped with interfaces and software developed by Scandrett and Gormezano (1980).

During each training session, each rabbit wore a muzzle-like headset that fitted securely about the snout and supported a photoelectric transducer for detecting movements of the NM. A small tinned copper wire hook was attached to a silk loop sutured into the NM of the rabbit's right eye. The other end of the hook was connected to an L-shaped crank that operated the photoelectric transducer (Gormezano \& Gibbs, 1988). The signal from the phototransistor was amplified and transmitted to an analog-digital converter (10-msec sample rate) installed in the computer.

\section{Procedure}

All the rabbits received 1 day of preparation, 2 days of recovery, 1 day of adaptation, and 23 days of training and testing. On the preparation day, hair surrounding each rabbit's right eye was removed, and a small loop of surgical silk (000 Dynex) was sutured into the NM of the right eye using a local anesthetic (proxymetacaine hydrochloride). The rabbits were returned to their home cages for 2 days of recovery following preparation. On the adaptation day, the rabbits were placed in the conditioning apparatus for $60 \mathrm{~min}$, but no stimuli were presented.

On the day following adaptation, the rabbits were randomly assigned to one of four groups designated Rest, RAQ-300, RAQ-600, and RAQ-1,200. In brief, Groups RAQ-300, RAQ-600, and RAQ1,200 received the number of extinction trials indicated by their respective group names before they received reacquisition training with the original CS, and Group Rest was the naive, rest control group.

In Stage 1, which lasted for 1 day, Groups RAQ-300, RAQ-600, and RAQ-1,200 received $45 \mathrm{CS}-\mathrm{US}$ trials $(\mathrm{A}+$, where A indicates the CS and + indicates the US). The CS-US interval (onset to onset) was $250 \mathrm{msec}$ long. The intertrial interval (ITI) was $60 \mathrm{sec}$ long (range, 50-70 sec). Group Rest was placed in the conditioning apparatus for $45 \mathrm{~min}$ but received neither the CS nor the US.

In Stage 2, which lasted for 20 days, Groups RAQ-300, RAQ-600, and RAQ-1,200 received extinction training. For the first 15 days of Stage 2, Group RAQ-300 was placed in the conditioning apparatus for $60 \mathrm{~min}$ but received neither the CS nor the US. However, for the last 5 days of Stage 2, Group RAQ-300 received 60 CS-alone (A-, where - indicates the absence of the US) extinction trials per session. For the first 10 days of Stage 2, Group RAQ-600 was placed in the conditioning apparatus for $60 \mathrm{~min}$ but received neither the CS nor the US. However, for the last 10 days of Stage 2, Group RAQ-600 received $60 \mathrm{~A}-$ trials per session. Group RAQ-1,200 received 60 A - trials per session on all 20 days of Stage 2 training. In summary, for each of the reacquisition groups, extinction training was conducted just before Stage 3 in order to avoid any conceivable retention loss for any impact of extinction on subsequent reacquisition (see Schachtman, Threlkeld, \& Meyer, 2000). Finally, Group
Rest was placed in the conditioning apparatus for $60 \mathrm{~min}$ but received neither the CS nor the US on any of the 20 days of Stage 2.

In Stage 3, which lasted for 2 days and was the same for all groups, each daily training session consisted of six 10-trial blocks. Each block contained nine $\mathrm{A}+$ presentations and 1 test trial in which the CS was presented alone.

\section{Response Definition}

A CR was defined as any extension of the NM greater than or equal to $0.5 \mathrm{~mm}$ that occurred following the onset of the CS but prior to its termination (Marshall-Goodell, Schreurs, \& Gormezano, 1982).

\section{Results}

Except as otherwise noted, planned contrasts were used to analyze the data, and the rejection level was set according to a Type I error rate of .05 (O’Brien \& Kaiser, 1985). One animal in Group Rest had to be removed from the experiment due to a leg injury incurred on the preparation day, and thus, the size of that group was reduced to 7 animals. Figure 1 depicts mean percent CR during the three stages of Experiment 1.

\section{Stage 1: Initial Acquisition}

In Stage 1 (see Figure 1A), Groups RAQ-300, RAQ600, and RAQ-1,200 all achieved mean levels around $50 \%$ CRs $( \pm 15 \%$ SEM $)$ within 45 trials. Any apparent differences among the groups were small and not significant $\left(F_{\mathrm{S}}<1\right)$.

\section{Stage 2: Extinction}

Figure $1 \mathrm{~B}$ shows the course of $\mathrm{CR}$ extinction. By the 3rd day of extinction training for each group, extinction appeared complete. The highest mean level of responding in any trial block after the 2 nd day of extinction training was $4 \% \mathrm{CRs}( \pm 1.9 \%$ SEM), which is consistent with the base level of spontaneous responding in the NM preparation (Gormezano, Kehoe, \& Marshall, 1983). Any apparent differences among the groups in their first 5 days of extinction were not statistically significant [largest $F(1,21)=1.83$ ].

\section{Stage 3: Reacquisition}

Between-groups comparisons. Figure $1 \mathrm{C}$ shows $\mathrm{CR}$ acquisition in Stage 3 for all four groups. The means are plotted in 10-trial blocks. (The percent CRs for each block were based on the 9 CS-US trials in each block; the data from the CS-alone test trials were excluded. A separate analysis of the data from the CS-alone trials yielded the same pattern of data as did that of the data from the CS-US trials, but with less statistical power.) Inspection of Figure $1 \mathrm{C}$ reveals that Groups RAQ-300, RAQ-600, and RAQ-1,200 reacquired responding faster than Group Rest acquired responding. Throughout most of the 1 st day of Stage 3, Groups RAQ-300 and RAQ-600 showed a higher level of responding than did either Group RAQ-1,200 or Group Rest. On the 2nd day, responding in all four groups converged to mean levels around $90 \%$ CRs.

The differences among groups on the early trials of Stage 3 can be seen more easily in Figure 1D. Figure 1D 

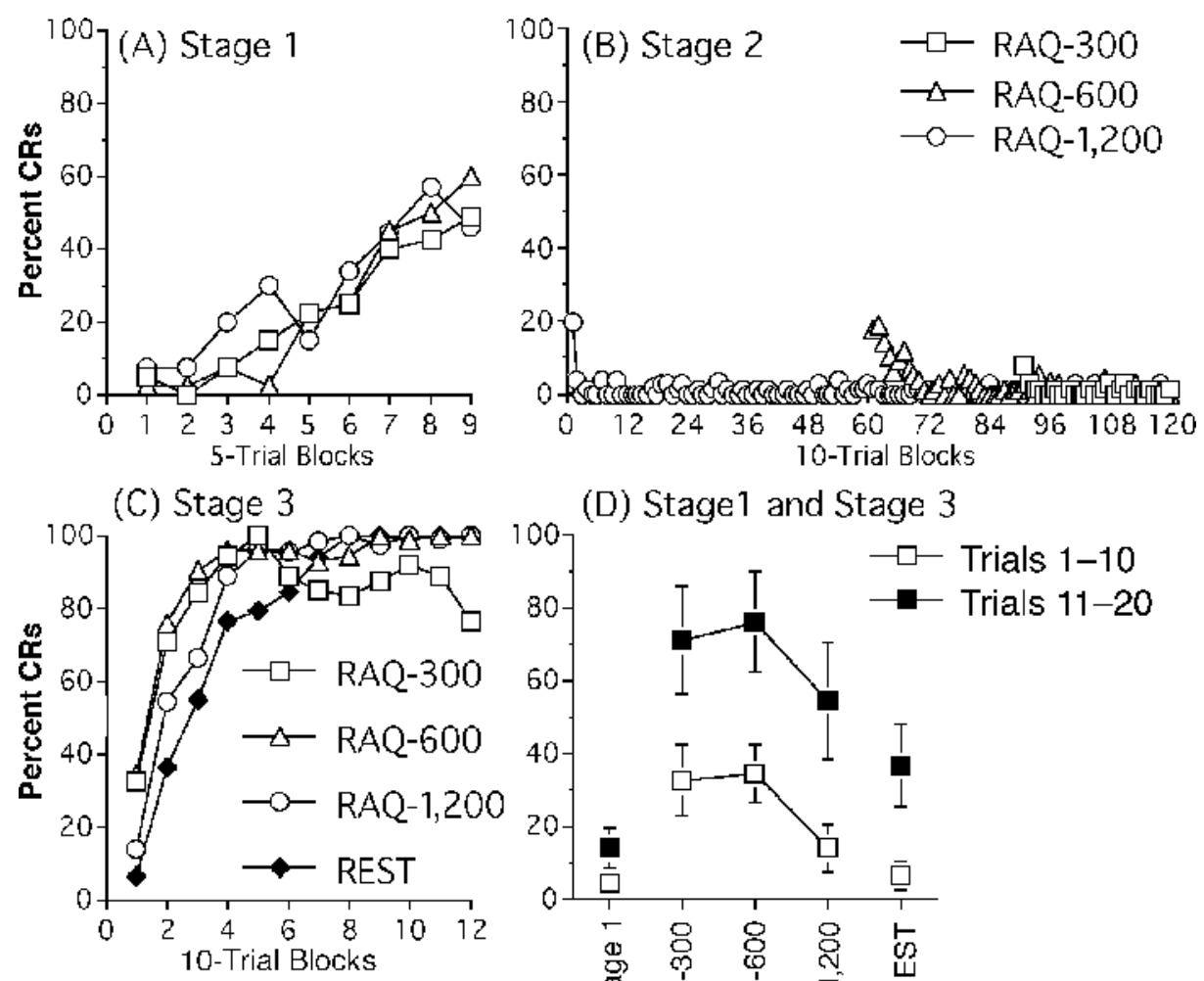

(D) Stage 1 and Stage 3



Figure 1. Percentage CRs of Groups RAQ-300, RAQ-600, RAQ-1,200, and Rest for the NM system in Stages 1, 2, and 3 of Experiment 1. Panel A shows responding in Stage 1, which is plotted in 5-trial blocks for the only day of Stage 1. Panel B shows responding in Stage 2; the data are plotted in 10-trial blocks, 6 for each day of training. Panel C shows responding in Stage 3; the data are plotted in 10-trial blocks, 6 for each day of training. The last trial of each 10 -trial block is omitted in Stage 3 because it was a test trial. Panel D shows responding for the first two 10-trial blocks of Stage 1 averaged across all three reacquisition groups, and the first two 10-trial blocks of Stage 3 as a function of the experimental groups. Error bars denote the standard errors of the mean.

shows the mean percent CRs $( \pm 1 S E M)$ in the first two blocks of Stage 3 as a function of groups (RAQ-300, RAQ600 , RAQ-1,200, and Rest). The left-hand point of this figure depicts the mean percent CRs in the corresponding trial blocks during initial acquisition training in Stage 1. Each of these points for Stage 1 is the average across all three groups that received initial CS-US training.

In the first block of trials in Stage 3, Group RAQ-300 showed a mean level of $33 \%$ CRs $( \pm 9.7 \%$ SEM), which was similar to that of Group RAQ-600 $(M=34 \%$ CRs $\pm 8.1 \% S E M)$, slightly higher than that of Group RAQ$1,200(M=14 \% \mathrm{CRs} \pm 6.7 \% S E M)$, and considerably higher than that of Group Rest $(M=6 \%$ CRs $\pm 4.1 \%$ $S E M)$. The same pattern of responding was maintained across the second block of trials in Stage 3, albeit at a higher overall level. In summary, as the number of extinction trials increased, there appeared to be a graded reduction in the rate of reacquisition relative to that of the rest control group.

Statistical comparisons confirmed the apparent differences among the groups. On the 1 st day of Stage 3, responding in both Group RAQ-300 and Group RAQ600 was significantly greater than that in Group Rest $\left[F_{\mathrm{S}}(1,27)=4.23,5.39, p \mathrm{~s}<.05\right]$. Group RAQ-1,200's performance appeared intermediate between that of Group Rest and that of Group RAQ-600. However, Group RAQ1,200 's level of responding failed to differ significantly from that of either Group Rest $[F(1,27)=1.40, p>.20]$ or that of Group RAQ-600 $[F(1,27)=1.39, p>.20]$.

Stage 1 versus Stage 3. Further inspection of Figure 1D indicates that all groups, including Group Rest, appeared to show more responding in Stage 3 than in Stage 1. Among the reacquisition groups, a within-subjects comparison of performance during the first two blocks of Stage 1 versus the first two blocks of Stage 3 revealed a significant main effect of stage $[F(1,21)=61.00, p<$ .05]. A simple effects analysis on the basis of group revealed that responding was greater during reacquisition than during acquisition in all three reacquisition groups [smallest $F(1,7)=5.64, p$ s $<.05$ ].

Finally, a between-groups analysis was conducted, in which the first two blocks of training for Group Rest in 
Stage 3 were compared with the first two blocks of training in the other three groups in Stage 1. Group Rest, having received 22 days of exposure to the apparatus, appeared to show faster initial CR acquisition than did the reacquisition groups, which had had only 1 day of exposure to the apparatus. This apparent difference approached but did not reach the declared level of significance $[F(1,27)=3.96, p<.10]$.

\section{Discussion}

Experiment 1 resulted in two complementary findings. First, even after brief initial acquisition and extensive extinction, rapid reacquisition still appeared in the rabbit NM preparation. Ratios of extinction trials to acquisition trials of 7:1 (Group RAQ-300) and 13:1 (RAQ-600) yielded significant rapid reacquisition in comparison with both a rest control and initial acquisition. Second, there was evidence that rapid reacquisition could be diminished by even more extended extinction. Using a ratio of 27:1, Group RAQ-1,200's reacquisition was more rapid than its own initial acquisition, but failed to significantly exceed that of Group Rest.

These results confirm and extend the recent findings of Medina et al. (2001) in the rabbit eyelid preparation. They report that, for a 9:1 ratio of extinction trials to acquisition trials, reacquisition was rapid on the basis of a within-subjects comparison between reacquisition and initial acquisition. The present experiment found a similar result, with even greater ratios, of 13:1 and 27:1. However, when compared with the rest control group, the group that received a 27:1 ratio (Group RAQ-1,200) failed to attain significant rapid reacquisition. Given that the rest control group was potentially subject to facilitation in CR acquisition as a result of latent inhibition of the context, the failure to see rapid reacquisition at the 27:1 ratio may not be the absolute outer boundary. Nevertheless, the graded reduction across reacquisition groups suggests that, at some point, it may be possible to eliminate rapid reacquisition.

The present experiment was an attempt to duplicate the chief features of designs that have yielded slow reacquisition in the past. Specifically, initial training was brief, and extinction was extended. In comparison with previous findings of slow reacquisition in conditioned suppression using a 9:1 ratio (Bouton, 1986) and appetitive conditioning using an 11:1 ratio (Ricker \& Bouton, 1996), a much greater ratio, of $27: 1$, in the present experiment, perhaps eliminated rapid reacquisition but did not retard it. Of course, it is conceivable that even more extended extinction might have eventually yielded slow reacquisition. This tactic, however, is infinitely regressive and, at the extreme, could become confounded with problems associated with geriatric rabbits (Coffin \& Woodruff-Pak, 1993).

\section{EXPERIMENT 2}

Rather than embark on the task of using even more massive extinction for the rabbit NM response, in Ex- periment 2 we examined reacquisition in HR conditioning following brief acquisition and various amounts of extinction. It has become conventional to distinguish between response systems that show fast initial conditioning and those that show slower initial conditioning (Lennartz $\&$ Weinberger, 1992). Response systems that have shown slow reacquisition on at least some occasions, such as taste-aversion learning (Hart et al., 1995), conditioned suppression (Bouton, 1986), and appetitive conditioning (Ricker \& Bouton, 1996), would generally be classified as fast response systems. Similarly, rabbit HR conditioning shows substantial acquisition and extinction within a handful of trials (Schneiderman, 1972; see Lennartz \& Weinberger, 1992, 1994, for extensive comparisons of conditioning in different response systems, including $\mathrm{HR}$ in the rabbit.) Moreover, the rabbit HR conditioning relies on different neural pathways than NM conditioning does, even when the same CSs and USs are used for both systems (Kapp, Whalen, Supple, \& Pascoe, 1992; Schneiderman et al., 1987). Finally, reacquisition has never been examined in rabbit HR conditioning. Hence, there were good empirical and theoretical reasons for examining reacquisition in HR conditioning.

The design of Experiment 2 was conceptually identical to that of Experiment 1, but some changes were needed to accommodate the particular features of the rabbit HR preparation. Unlike the NM response, HR is susceptible to nonassociative contributions-for example, orientation responses and pseudoconditioning. The initial orienting response to a CS is decelarative (bradycardic), and subsequently, it habituates with repeated presentation of the CS (Schneiderman et al., 1987; Schneiderman, Smith, Smith, \& Gormezano, 1966). The HR CR is also bradycardic. Hence, acquisition of a bradycardic CR to a CS can be masked by the habituation of the bradycardic orienting response to the same CS. Therefore, it is difficult to distinguish associative from nonassociative effects on HR without an appropriate control for estimating changes in the orienting response as well as other nonassociative contributors (Powell \& Lipkin, 1975). A conventional method for estimating nonassociative contributions on a within-subjects basis is to use differential conditioning (Gormezano, 1966). Accordingly, the reacquisition groups received nonreinforced presentations of an alternative stimulus (B) intermixed with presentations of the target stimulus (A) in a $1: 1$ ratio.

Apart from the addition of the nonreinforced stimulus $(\mathrm{B}-)$, the design of Experiment 2 paralleled that of Experiment 1 . That is, the reacquisition groups received brief initial training that consisted of 1 day of initial acquisition training that contained 15 pairings of a reinforced stimulus $(\mathrm{A}+)$, plus the 15 presentations of a nonreinforced stimulus $(\mathrm{B}-)$. This initial acquisition day was followed by 5,10 , or 20 days of extinction training and then by 4 days of reacquisition of the HR discrimination (RAQH). These groups were designated RAQH75, RAQH-150, and RAQH-300, respectively. On each day of extinction training, there were 15 presentations of 
each stimulus in the absence of reinforcement $(\mathrm{A}-$, $\mathrm{B}-$ ). Hence, the ratios of $\mathrm{A}-$ extinction trials to $\mathrm{A}+\mathrm{ac}-$ quisition trials were 5:1,10:1, and 20:1 for the three groups, respectively. The naive acquisition group was designated as Rest. This group received exposure to the apparatus during the first two stages of training and then received 15 pairings of the reinforced stimulus $(\mathrm{A}+)$ and 15 presentations of the nonreinforced stimulus $(\mathrm{B}-)$ on each day in the final stage of training.

\section{Method}

Subjects

The subjects were 32 experimentally naive male, albino rabbits.

\section{Apparatus and Procedure}

Except as otherwise specified, the apparatus and procedure were identical to those of Experiment 1. The CSs were a 500-Hz, 94-dB (SPL) tone and a 5000-Hz, 94-dB (SPL) tone. Both the CSs were of 4,000-msec duration throughout all three stages of the experiment. To transduce HR, an Autoclip wound clip was attached to the skin on the left haunch about $40 \mathrm{~mm}$ from the spine and to the right shoulder about $40 \mathrm{~mm}$ from the spine. The two electrodes were separated by approximately $150 \mathrm{~mm}$. Electrolyte gel (Hewlett-Packard Redux Creme for electrocardiography) was applied to the skin, and wound clips were applied to improve signal quality. Leads attached to wound clips carried the HR signal to a preamplifier mounted in the chamber and, subsequently, to a Mac Lab 8s v1.0.5 (software: Chart v 3.5.2/sec) and a Macintosh Performa 5400/180 computer, where the frequency and interbeat interval of each rabbit's HR were recorded.

All of the rabbits received 1 day of preparation, 1 day of adaptation, and 25 days of training and testing. On the preparation day, a $2-\mathrm{cm}^{2}$ patch of hair was shaved from the left haunch and the right shoulder of each animal. On the adaptation day, the rabbits were placed in the conditioning apparatus for $60 \mathrm{~min}$, but neither a CS nor a US was presented.

On the day following adaptation, the rabbits were randomly assigned to one of four groups designated RAQH-75, RAQH-150, RAQH-300, and Rest. In brief, Groups RAQH-75, RAQH-150, and RAQH-300 received reacquisition of a differential discrimination after the number of A- extinction trials indicated by their names, and Group Rest was the naive, rest control group.

In Stage 1, which lasted for 1 day, Groups RAQH-75, RAQH150 , and RAQH-300 received 15 pairings of the A stimulus with the US $(\mathrm{A}+)$ and 15 presentations of the $\mathrm{B}$ stimulus in the absence of reinforcement $(\mathrm{B}-)$. For half of the animals in Groups RAQH-75, RAQH-150, and RAQH-300, the $500-\mathrm{Hz}$ tone was the A stimulus and the $5000-\mathrm{Hz}$ tone was the B stimulus. For the other half of the animals in Groups RAQH-75, RAQH-150, and RAQH-300, this assignment was reversed. The CS-US interval (onset to onset) on reinforced trials was $4,000 \mathrm{msec}$. The mean ITI was $100 \mathrm{sec}$ (range, $90-110 \mathrm{sec}$ ). Group Rest was placed in the conditioning apparatus for $60 \mathrm{~min}$ but received neither CSs nor the US. HR was recorded on every $\mathrm{A}+$ trial and every $\mathrm{B}-$ trial.

Stage 2 lasted for 20 days. For the first 15 days of Stage 2, Group RAQH-75 was placed in the conditioning apparatus for $60 \mathrm{~min}$ but received neither of the CSs nor the US. However, for the last 5 days of Stage 2, Group RAQH-75 received $15 \mathrm{~A}$ - and $15 \mathrm{~B}$ - presentations per day. For the first 10 days of Stage 2, Group RAQH-150 was placed in the conditioning apparatus for $60 \mathrm{~min}$ but received neither of the CSs nor the US. However, for the last 10 days of Stage 2, Group RAQH-150 received $15 \mathrm{~A}-$ and $15 \mathrm{~B}-$ presentations per day. Group RAQH-300 received $15 \mathrm{~A}-$ and $15 \mathrm{~B}-$ presentations per day on all 20 days of Stage 2. Group Rest continued to sit restrained in the conditioning apparatus on all 20 days of Stage 2. HR was recorded for every $\mathrm{A}-$ and $\mathrm{B}-$ trial.
In Stage 3, which lasted for 4 days, all groups received $15 \mathrm{~A}+$ and $15 \mathrm{~B}-$ presentations per day. For half of the animals in Group Rest, the A stimulus was the $500-\mathrm{Hz}$ tone and the B stimulus was the $5000-\mathrm{Hz}$ tone, and for the other half of the animals, this assignment was reversed. HR was recorded on every A+ trial and every $\mathrm{B}-$ trial for all groups.

On each trial, there were two recording periods: one for $4 \mathrm{sec}$ immediately before CS onset, and one for the 4-sec duration of the CS, terminating at the onset of the US. The sampled heart voltage signals were submitted to a digital threshold procedure to detect Rwaves of the cardiogram and were then visually inspected, after which remaining muscle artifacts were removed. A heartbeat was defined as the interval between successive R-peaks, provided that the interval was less than $400 \mathrm{msec}(\geq 2.5 \mathrm{bps})$ and greater than $180 \mathrm{msec}(\leq 5.5 \mathrm{bps})$. This range restriction was imposed to eliminate movement-related artifacts that caused the software to either interpret noise in the recording as a series of rapid heartbeats or to miss small R-peaks, thus doubling the interbeat interval.

\section{Results}

Except as otherwise noted, planned contrasts were used to analyze the data, and the rejection level was set according to a Type I error rate of .05. One animal in Group Rest had to be removed from the experiment due to a leg injury incurred on the preparation day, and thus, the size of that group was reduced to 7 animals. The results from 1 animal in Group RAQH-300 in Stage 1 were not recorded properly due to a computer error, and so the size of that group was reduced to 7 animals in Stage 1 only.

\section{Stage 1: Initial Acquisition}

Figure 2 shows the HR ( \pm 1 SEM) averaged over the 4sec duration of the CS for each day for all three stages of the experiment. HR is expressed as a percentage change in HR frequency relative to the resting HR recorded for $4 \mathrm{sec}$ before CS onset. The left-hand set of points in each panel depicts responding to $\mathrm{A}+$ and $\mathrm{B}-$ trials during Stage 1. Groups RAQH-75, RAQH-150, and RAQH-300, showed acquisition of bradycardia (reduced HR) to the A+ stimulus. As can be seen in Figure 2, Groups RAQH75, RAQH-150, and RAQH-300 collectively showed significant discriminative responding to $\mathrm{A}+$ versus $\mathrm{B}-$ in Stage $1[F(1,20)=67.19, p<.01]$. Any apparent differences among the groups in responding to $\mathrm{A}+$ versus $\mathrm{B}-$ were small and not statistically significant [largest $F(1,20)=3.02, p>.05]$.

\section{Stage 2: Extinction}

The middle set of points in each panel of Figure 2 depicts responding to $\mathrm{A}-$ and $\mathrm{B}-$ trials in Stage 2 extinction in Groups RAQH-75, RAQH-150, and RAQH-300. Discriminative responding to the $\mathrm{A}-$ and $\mathrm{B}-$ stimuli decreased over the course of extinction training. By the 4th day of extinction in each group, responding to the previously reinforced Stimulus A converged with that to Stimulus B. Statistical analysis of responding in the first 5 days of extinction for each group confirmed this convergence [stimulus (A vs. B) $\times$ days (linear trend); $F(1,21)=46.42, p<.01]$. By Day 21 , the last day of extinction training, discriminative responding to $\mathrm{A}-$ and 

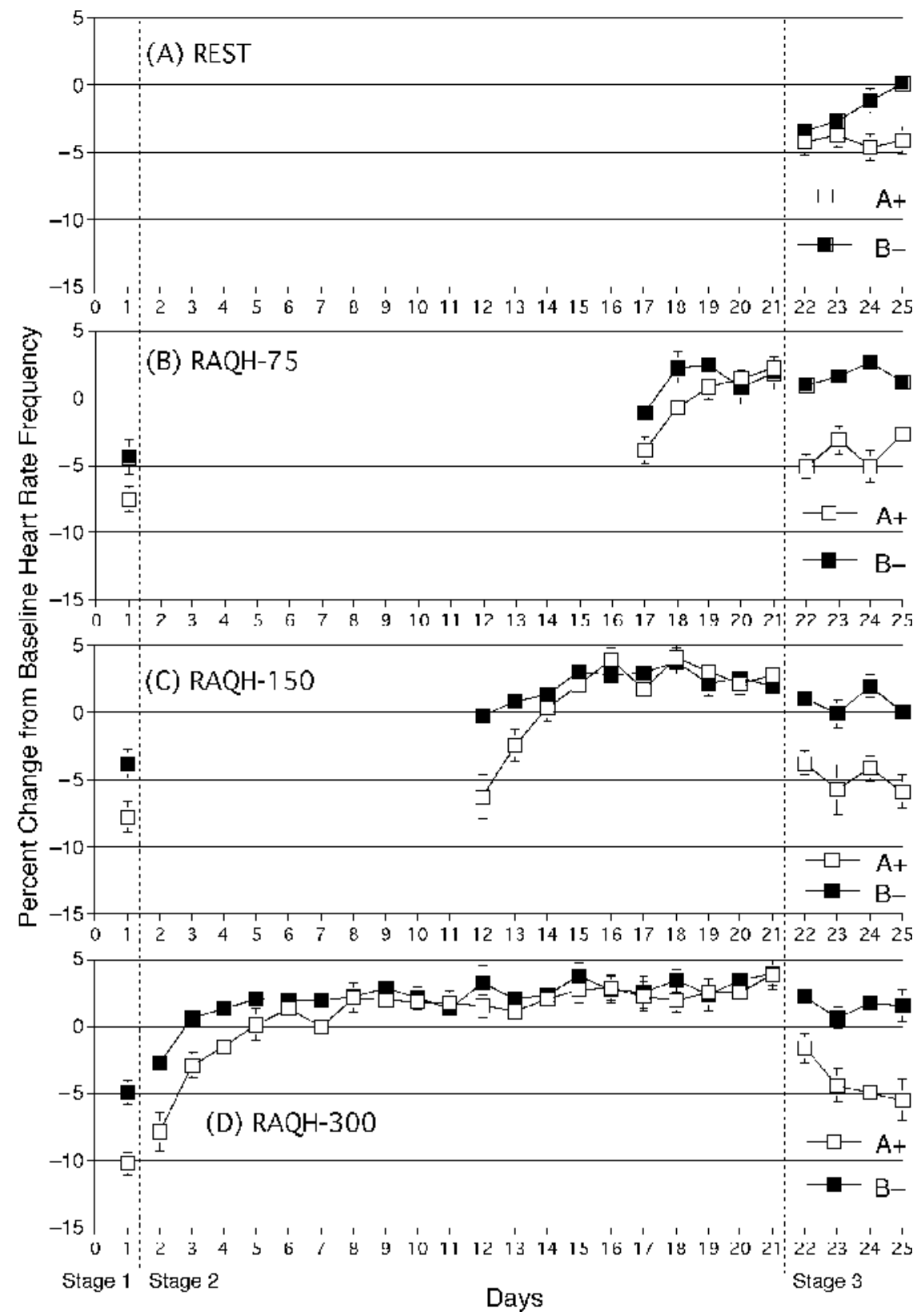

Figure 2. Mean heart rate (HR) of Groups Rest (panel A), RAQH-75 (panel B), RAQH150 (panel C), and RAQH-300 (panel D) are expressed as a percentage of change relative to resting HR. A mean is plotted for each day of training, which was calculated by averaging the percentage change in HR over the 4-sec duration of the CS, across all 15 trials of each trial type on that day. All three stages of Experiment 2 are shown for each group. Error bars denote the standard errors of the mean.

B- had disappeared, and extinction appeared complete. Any differences among the three groups were small, unsystematic, and not statistically significant $\left(F_{\mathrm{S}}<1\right)$.

\section{Stage 3: Reacquisition}

Between-groups comparisons. The right-hand set of points in each panel of Figure 2 shows discriminative responding to the A+ versus B - trials in Stage 3. Rapid reacquisition of discriminative responding in comparison with the control group appeared in all three reacquisition groups. Over all of Stage 3, discriminative responding was significantly greater in Group RAQH-75, Group RAQH-150, and Group RAQH-300 than in Group Rest, which showed little discriminative responding until the last 2 days of Stage 3 [smallest $F(1,27)=5.39, p \mathrm{~s}<.05$ ]

Further inspection of the pattern of responding in Stage 3 suggests that there was a graded effect of the number of extinction trials. Specifically, Group RAQH-75, 
which had the fewest extinction trials, showed the greatest discrimination on the 1st day of Stage 3. Group RAQH-150, which had the intermediate number of extinction trials, achieved a moderate, stable level of discriminative responding starting from the 1st day of Stage 3 . Finally, Group RAQH-300, which had the largest number of extinction trials, also achieved a moderate level of discriminative responding on the 1 st day of Stage 3 , after which its discrimination grew even greater across Stage 3. Statistical comparisons confirmed that there was a significant groups (linear trend) $\times$ stimulus $(\mathrm{A}+$ vs. $\mathrm{B}-) \times$ days (linear trend) interaction $[F(1,27)=$ $6.56, p<.05]$.

Stage 1 versus Stage 3. Although reacquisition in all three reacquisition groups was rapid relative to that of Group Rest in Stage 3, further examination of Figure 2 reveals two unexpected features when responding in Stage 3 is compared with responding in Stage 1. First, acquisition by Group Rest in Stage 3 appeared slower than initial acquisition by the reacquisition groups in Stage 1. For example, in Stage 3, Group Rest showed hardly any differentiation between A + versus B - until Day 24, the 3rd day of Stage 3. A post hoc analysis indicated that Group Rest failed to show significant differentiation on their 1st day of acquisition training (Day 22, $F<1$ ). In contrast, the reacquisition groups in Stage 1 all showed significant differentiation between $\mathrm{A}+$ and $\mathrm{B}-$ on their day of initial acquisition training [smallest $F(1,7)=$ $13.15, p \mathrm{~s}<.01$ for all three reacquisition groups]. Second, the three reacquisition groups showed similar degrees of discrimination on the 1st day of Stage 3 versus on the day of initial acquisition training in Stage 1. In fact, the interaction of stage and stimulus $(\mathrm{A}+\mathrm{vs} . \mathrm{B}-$ ) was not significant $[F(1,20)=1.08, p>.10]$.

As has been seen in previous research (Schneiderman et al., 1987; Schneiderman et al., 1966), the overall bradycardic response was influenced by habituation of a bradycardic orienting response to both discrete stimuli. The bradycardic response to both $\mathrm{A}+$ and $\mathrm{B}-$ was greater on Day 1 than on Day 22. Specifically, the bradycardia on Day 1 averaged across stimuli and reacquisition groups was $-6.5 \%( \pm 0.57 \% S E M)$. In contrast, the bradycardia on Day 22 was $-1.1 \%( \pm 0.45 \%$ SEM). The statistical comparisons confirmed that there was a significant main effect of stage $[F(1,20)=21.87, p<.01]$. This diminution in the bradycardic response appeared attributable to the presentation of the stimuli, because Group Rest, which had the same exposure to apparatus, showed a bradycardic response to both stimuli when they were first introduced to this group at the start of Stage 3 .

The smaller bradycardic response in Stage 3 in comparison with that in Stage 1 may have also reflected changes in baseline HR across days of training. To test this hypothesis, HR prior to CS presentations was examined for Stage 1 (Day 1), the last day of Stage 2 (Day 21), and the 1st day of Stage 3 (Day 22) for all groups, including Group Rest. There was a significant main effect of stage on baseline HR. Specifically, baseline HR was significantly greater on Day $1(M=4.34$ bps \pm 0.06 $S E M)$ than on either Day $21(M=4.14 \mathrm{bps} \pm 0.06 S E M)$ or Day $22[M=4.17 \mathrm{bps} \pm 0.06 S E M ; F \mathrm{~s}(1,26)=13.01$, $8.59, p \mathrm{~s}<.05]$. Any apparent differences between groups were not significant [largest $F(1,26)=1.64, p>.10]$. In addition, the interaction of stage and group, which would have indicated an effect of extinction trials on baseline $\mathrm{HR}$, failed to reach significance [largest $F(1,26)=1.39$, $p>.10]$.

\section{Discussion}

Experiment 2 resulted in two complementary findings similar to those of Experiment 1. First, reacquisition of the HR conditioned discrimination in all three groups proceeded significantly faster than did acquisition in the rest control group despite a limited amount of initial acquisition training and extended extinction training, up to a ratio of 20:1 extinction trials for each acquisition trial. Second, the rate of reacquisition of discriminative responding was graded as a function of the number of extinction trials.

The use of between-subjects comparisons is conventional for transfer experiments (Bouton, 1986; Osgood, 1953, pp. 520-521). In Experiment 1 and in previous studies with the NM preparation, such between-subjects differences have had parallel, within-subjects differences between initial acquisition and reacquisition (see, e.g., Napier et al., 1992). In the present experiment, a different pattern emerged; the within-subjects comparison indicated that reacquisition was about as fast as original acquisition.

The source of this discrepancy may be related to the reduction in baseline HR during the course of the experiment. At a methodological level, the reduction in baseline HR may have introduced a floor effect. Although the average baseline HR in the rabbit is relatively high ( $>4 \mathrm{bps}$ ), there may be a physiological floor of its normal levels. Because conditioning in the HR preparation is expressed as a reduction in HR, a lower baseline would leave less room for detection of further reduction in HR. In Stage 1, when the baseline rate was higher, the bradycardic response was, on average, $-9 \%( \pm 0.6 \%$ SEM $)$ for $\mathrm{A}+$ and $-4 \%( \pm 0.6 \%$ SEM $)$ for B - . In Stage 3, when the baseline was lower, the average response in the reacquisition groups was $-4 \%( \pm 0.6 \% S E M)$ for $\mathrm{A}+$ and $+1 \%( \pm 0.3 \% S E M)$ for $\mathrm{B}-$. Thus, the similarity in the rate of reacquisition versus that of initial acquisition in the reacquisition groups was confounded by differences in the baseline HR at different stages in training. Hence, the conventional comparison between Group Rest and the reacquisition groups in Stage 3 was the meaningful comparison, because it equated all the groups for their baseline HR as well as for their exposure to the apparatus.

\section{EXPERIMENT 3}

Whereas in Experiments 1 and 2 we examined reacquisition after extended extinction, in Experiment 3 we 
examined the other two forms of savings-namely, CMA and concurrent recovery. Both of these phenomena expose residual excitatory associative strength without, however, pairing the original CS with the US, as is done in reacquisition training. In this way, Experiment 3 was designed to provide converging evidence for the effects of extended extinction after brief acquisition training.

Stages 1 and 2 of Experiment 3 were identical to the corresponding stages of Experiment 1 . Specifically, the CMA experimental groups received 45 CS-US acquisition trials for the NM response, followed by 300,600 , or 1,200 CS-alone extinction trials. In Stage 3, all three experimental groups received reinforced training with a CS from a different sensory modality to determine whether any cross-modal savings could be detected. The experimental groups also received nonreinforced tests with the original CS to reveal any concurrent recovery. For example, animals that had received the tone CS in Stages 1 and 2 received pairings of a light CS with the US in Stage 3 plus tests with the tone CS. As in Experiment 1, there was a naive rest control group that received exposure to the apparatus during the first two stages of training and then received CS-US pairings in Stage 3 plus nonreinforced tests with the alternative stimulus. In all four groups, tone and light were used as the two CSs in a counterbalanced fashion.

\section{Method \\ Subjects \\ The subjects were 32 experimentally naive male, albino rabbits.}

\section{Apparatus and Procedure}

Except as otherwise specified, the apparatus and procedure were identical to those of Experiment 1. The CSs were a 1000-Hz, 94-dB (SPL) tone and a $20-\mathrm{Hz}$ flashing of the houselight, which was provided by the $8-\mathrm{W}$ neon light tube, mounted approximately $3 \mathrm{~cm}$ anterior and $20 \mathrm{~cm}$ above the subject's head. The ambient visual condition was houselight on. Both the CSs were of 250-msec duration throughout all three stages of the experiment. All rabbits received 1 day of preparation, 2 days of recovery, 1 day of adaptation, and 25 days of training and testing. On the day following adaptation, each rabbit was randomly assigned to one of four groups $(n=8)$ designated Rest, CMA-300, CMA-600, and CMA-1,200.

In Stage 1, which lasted for 1 day, Groups CMA-300, CMA-600, and CMA-1,200 received 45 CS-US trials. For half of the animals in each group, the CS was the tone. For the other half, the CS was the light. Group Rest was placed in the conditioning apparatus for $45 \mathrm{~min}$ but received neither the CS nor the US.

In Stage 2, which lasted for 20 days, Groups CMA-300, CMA600 , and CMA-1,200 received 300, 600, and 1,200 CS-alone presentations, respectively, distributed in exactly the same manner as for the corresponding groups in Experiment 1. Group Rest was placed in the conditioning apparatus for $60 \mathrm{~min}$ but received neither the CS nor the US on any of the 20 days of Stage 2.

In Stage 3, which lasted for 3 days, each daily training session consisted of six 10-trial blocks. Each block contained nine pairings of the new CS with the US and one nonreinforced test trial of the original CS. Thus, the animals trained originally with the tone CS received training with the light CS, and vice versa. In Group Rest, half the animals received training with the tone CS, and half the animals received training with the light CS. In addition, each session contained two test trials of the original CS, which were presented at the very beginning of each session.

\section{Results}

One animal from each of Groups Rest, CMA-300, and CMA-1,200 had to be removed from the experiment due to injuries incurred on the preparation day, thus reducing the size of each group to 7 animals.

\section{Stage 1: Initial Acquisition}

Figure 3 is organized in the same fashion as Figure 1. In Stage 1 (see Figure 3A), Groups CMA-300, CMA-600, and CMA-1,200 achieved mean levels of around $60 \%$ CRs $( \pm 7.9 \%$ SEM $)$ within 45 trials. Any apparent differences among groups were small and nonsignificant $\left(F_{\mathrm{S}}<1\right)$.

\section{Stage 2: Extinction}

Figure $3 \mathrm{~B}$ shows the course of CR extinction plotted in blocks of 10 trials. By the last day of Stage 2, extinction was complete in all three groups. The highest mean level of responding in any trial block after Day 3 of extinction training was $3 \% \mathrm{CRs}( \pm 2.6 \% S E M)$. However, as can be seen from Figure 3B, there were differences between groups in the first few days of extinction training. Group CMA-1,200 showed far more responding on its first 3 days of CS-alone presentations than did either Group CMA-600 or Group CMA-300. Specifically, Group CMA-1,200 began CS-alone presentations on the 1 st day of Stage 2 without any retention interval. In the first block of extinction trials, it showed $40 \%$ CRs $( \pm 15.6 \%$ SEM). In contrast, Group CMA-600 had a 10-day retention interval in which it was exposed to the conditioning apparatus in the absence of the CS or the US. In its first block of extinction trials, it showed a mean level of $6 \%$ CRs ( $\pm 4.0 \%$ SEM). Finally, Group CMA-300, which had a retention interval of 15 days, also showed a mean level of $6 \%( \pm 5.8 \%$ SEM $)$ in its first block of extinction trials. Statistical comparisons confirmed this apparent difference by a significant interaction of groups (linear trend) and days [linear trend; $F(1,25)=5.21 p<.05$ ].

\section{Stage 3: Cross-Modal Acquisition}

Between-groups comparisons. Figure $3 \mathrm{C}$ shows $\mathrm{CR}$ acquisition in Stage 3 as a function of trial blocks. In comparison with Group Rest, Groups CMA-300, CMA600 , and CMA-1,200 appeared to show higher levels of responding. However, this evidence for cross-modal savings failed to reach statistical significance $[F s(1,25)=$ $1.74,0.60$, and $0.61, p s>.10]$. Likewise, any apparent differences among the three experimental groups were small and not statistically significant $(F \mathrm{~s}<1)$.

A closer inspection of the data reveals transient crossmodal savings in Group CMA-300. Figure 3D shows CR acquisition in the first two trial blocks of Stage 3. In the first block of trials, Group CMA-300 showed a mean level of $26 \%$ CRs $( \pm 7.8 \%$ SEM), which was higher than that of Group CMA-600 $(M=10 \%$ CRs, $\pm 4.1 \%$ SEM $)$, and considerably higher than that of Group CMA-1,200 $(M=6 \%$ CRs, $\pm 4.4 \%$ SEM $)$ and Group Rest $(M=6 \%$ CRs, $\pm 4.4 \%$ SEM). Statistical analysis confirmed these 


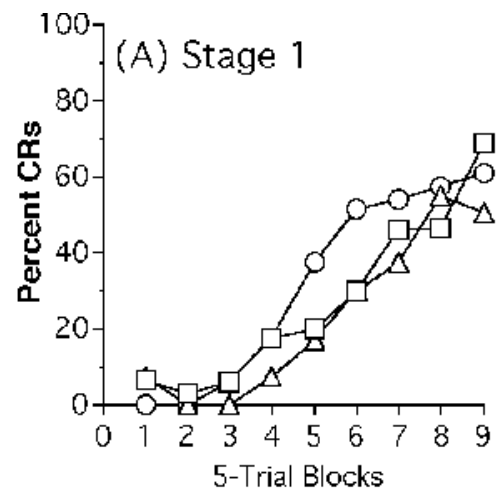

(C) Stage 3

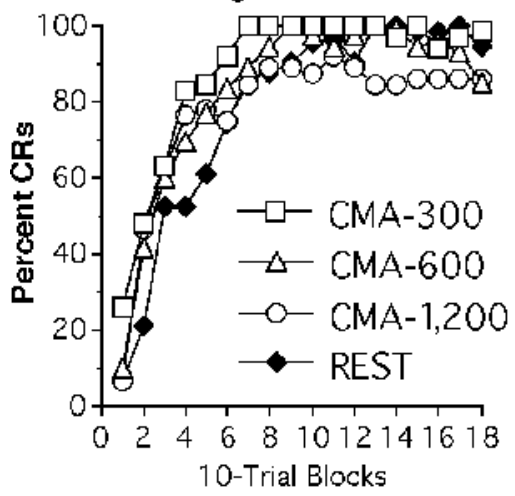

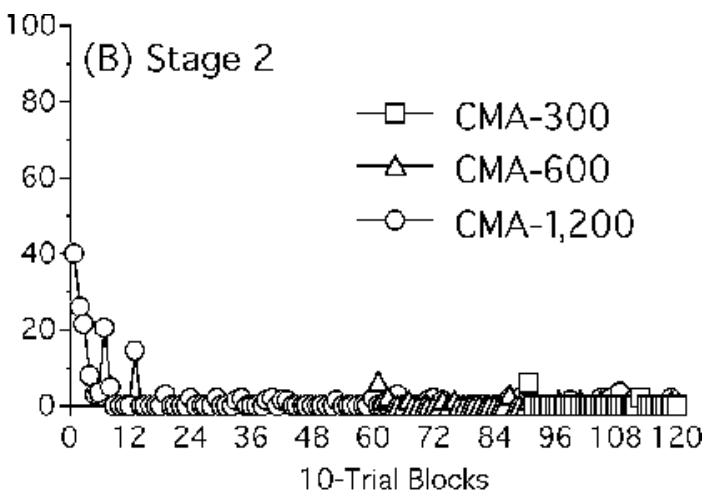

(D) Stage 1 and Stage 3

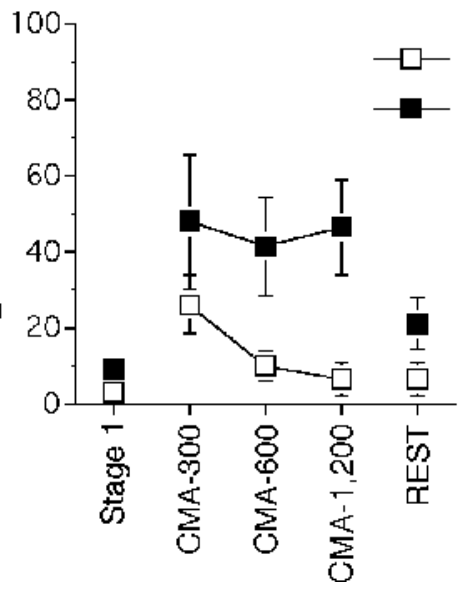

Figure 3. Percentage CRs of Groups CMA-300, CMA-600, CMA-1,200, and Rest for the NM system in Stages 1, 2, and 3 of Experiment 3. Panel A shows responding in Stage 1; the data are plotted in 5-trial blocks for the only day of Stage 1. Panel B shows responding in Stage 2; the data are

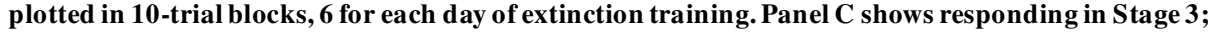
the data are plotted in 10-trial blocks, 6 for each day of cross-modal acquisition. The last trial of each 10-trial block in Stage 3 is omitted, because it was a test trial of the original CS. Panel D shows the percentage CRs for the first two 10-trial blocks of Stage 1 averaged across the three cross-modal acquisition groups and the first two 10 -trial blocks of $S$ tage 3 , as a function of the experimental groups. Error bars denote the standard errors of the mean.

group differences. Group CMA-300's responding was significantly greater than that of Group Rest $[F(1,25)=$ $5.73, p<.05]$. However, Groups CMA-600 and CMA1,200 failed to differ significantly from Group Rest $\left(F_{\mathrm{S}}<1\right)$. In addition, there was a linear trend in the level of responding as a function of the number of extinction trials $[F(1,25)=5.73, p<.05]$. In the second block of trials, Group Rest's performance remained lower than that of the cross-modal acquisition groups, but there were no statistically significant differences among the four groups [largest $F(1,25)=1.70, p>.10]$.

Stage 1 versus Stage 3. Further inspection of Figure 3D indicates that all groups appeared to show more responding in Stage 3 than they had in Stage 1. The left-hand point of Figure 3D depicts the mean percent CRs in the corresponding trial blocks during initial acquisition training in Stage 1. Each point is the average across all three groups that received initial CS-US training. A within-subjects comparison of performance during Stage 1 versus that during Stage 3 revealed a significant main effect $[F(1,19)=24.61, p<.05]$. A simple effects analysis revealed that responding was greater in Stage 3 during acquisition to the second stimulus than it was in Stage 1 acquisition to the first stimulus in all three experimental groups [smallest $F(1,6)=7.40, p \mathrm{~s}<.05$ ]

Finally, a between-groups analysis was conducted, in which the first two blocks of training for Group Rest in Stage 3 were compared with the first two blocks of training for the other three groups in Stage 1. Group Rest, having received 22 days of exposure to the apparatus, appeared to show faster initial CR acquisition than did the experimental groups, which had had only 1 day of exposure to the apparatus. For example, in Figure 3D, it can be seen that Group Rest showed a mean level of $21 \%$ CRs ( $\pm 6.9 \%$ SEM), whereas the experimental groups showed a mean level of $9 \% \mathrm{CRs}( \pm 2.9 \%$ SEM $)$ in Trials 


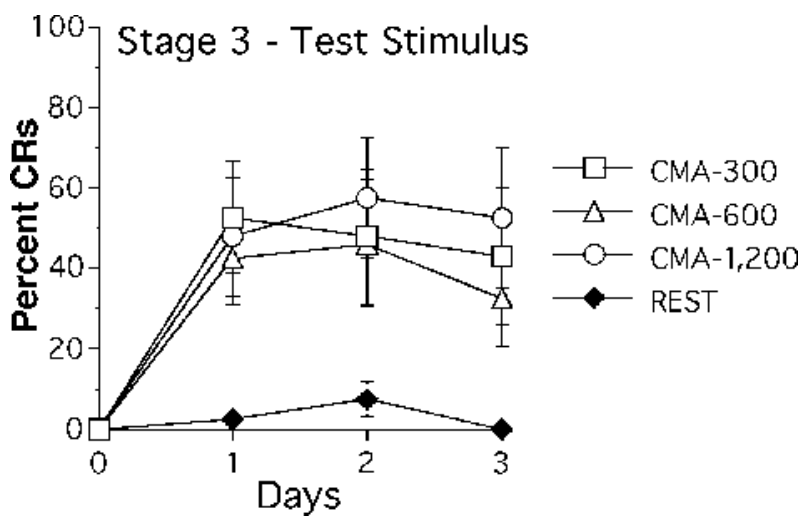

Figure 4. Percentage of CRs on tests of the alternative stimulus in Groups CMA-300, CMA-600, CMA-1,200, and Rest prior to the beginning of Stage 3 and then as a function of days in Stage 3 of Experiment 3.

11-20 in Stage 1. This apparent difference, however, approached but did not reach the declared level of significance $[F(1,25)=3.19, p<.10]$.

Stage 3: Concurrent Recovery. Figure 4 shows the results of the tests with the alternative stimulus during Stage 3 in Experiment 3. As can be seen in Figure 4, testing immediately before the beginning of CS-US pairings in Stage 3 revealed no spontaneous recovery in any of the groups to the original CS for the experimental groups. As CR acquisition proceeded to the new stimulus in Groups CMA-300, CMA-600, and CMA-1,200, all three groups recovered responding to their respective original CSs. In fact, within the 1 st day of Stage 3 , the mean CR likelihood in all three groups reached a level of around $47 \%$ ( $\pm 8.07 S E M)$, which approached their mean level of $60 \%( \pm 7.90$ SEM $)$ at the end of Stage 1. Statistical comparisons confirmed that Groups CMA-300's, CMA-600's, and CMA-1,200's mean levels of responding to the test stimulus were significantly greater than was that of Group Rest $(M=4 \% \pm 2.25$ SEM; smallest $F(1,25)=4.53, p s<.05]$. Any differences among the three experimental groups were small, unsystematic, and not statistically significant $\left(F_{\mathrm{S}}<1\right)$.

\section{Discussion}

Experiment 3 resulted in two paradoxical findings. First, when compared with acquisition in the rest control condition, facilitated cross-modal acquisition was shown to have been largely eliminated by the use of a combination of brief acquisition and extended extinction. With modest extinction (Group CMA-300), savings were still in evidence, albeit only in the first few trials of Stage 3 training with the new CS. Within-subjects comparisons between Stages 1 and 3 suggested that, even in Groups CMA-600 and CMA-1,200, there were perhaps some cross-modal savings. Second, in contrast to the modest cross-modal savings, concurrent recovery of CRs to the original CS was robust even in the face of the most ex- tended extinction. As was found in previous demonstrations of concurrent recovery, the level of responding to the original CS far exceeded any cross-modal stimulus generalization seen in the rest control group (Kehoe et al., 1995; Macrae \& Kehoe, 1999).

The modest evidence for facilitation of cross-modal acquisition in the present experiment stands in stark contrast to repeated previous demonstrations in the rabbit NM preparation that transfer across modalities survives extinction of responding to the original CS (Kehoe et al., 1995; Kehoe et al., 1984; Macrae \& Kehoe, 1999). In the previous studies, however, many more initial acquisition trials were used than in the present experiment. In addition, these studies typically used just enough $\mathrm{CS}$-alone trials to eliminate responding-usually around 300 extinction trials, which, even in the present experiment, still allowed for significant cross-modal savings. In the present experiment, the combination of a handful of acquisition trials combined with extensive extinction well past the disappearance of all responding seems to have located the lower boundary for cross-modal savings in the rabbit NM preparation.

Although extended extinction largely eliminated crossmodal savings, the robust nature of concurrent recovery nevertheless suggests that even a small amount of initial excitatory training goes a long way. Elsewhere in the rabbit NM preparation, there are other findings that indicate that brief initial excitatory training has a persistent impact on both reacquisition and cross-modal acquisition (Ross \& Scavio, 1983; Scavio, Ross, \& McLeod, 1983; Schreurs \& Kehoe, 1987).

In particular, the present results converge with the previous findings on two points. First, brief training with one stimulus appears to lay down a subthreshold association that can be activated by paired training with another, orthogonal stimulus. Second, this subthreshold association can be activated even when facilitation of CR acquisition to the new stimulus did not occur, as was the case for Groups CMA-600 and CMA-1,200 in the present experiment as well as for the group that received $15 \mathrm{~A}+$ trials in Schreurs and Kehoe (1987). The new information provided by the present experiment is that this subthreshold association can survive extensive extinction.

One unexpected result of the present experiment was that resistance to extinction in Stage 2 declined as a function of the retention interval between initial training and the start of extinction trials. Recall that all three experimental groups received 45 initial trials and then CSalone extinction trials after 0,10 , or 15 days of exposure to the apparatus. This exposure was designed to equate the total interval between Stage 1 and Stage 3 for all groups while manipulating the number of extinction trials.

The retention loss in Experiment 3 was unexpected for two reasons. First, it was not present in Experiment 1, in which both Stages 1 and 2 were identical to the corresponding stages of Experiment 3. Second, retention losses that have been seen previously for the rabbit NM preparation occurred under very different conditions. Specif- 
ically, Schreurs $(1993,1998)$ conducted two systematic studies of retention in the rabbit NM preparation. He conducted initial training over several days until responding reached asymptotic levels greater than $90 \%$ CRs. After initial training, the rabbits were housed in their home cages without exposure to the training apparatus, CS, or US for periods stretching up to 9 months. After 1 month, there was little or no evidence of a retention loss, and intervals of 6 to 9 months were required for responding to disappear entirely. Moreover, the retention losses were easily reversed. When the rabbits were reintroduced to the apparatus and tested with the CS alone, responding rose even in the absence of reinforcement, suggesting a reminder effect (Balaz, Gutsin, Cacheiro, \& Miller, 1982).

If the retention losses seen after brief training in the present experiment are reliable, the interpretative question becomes: Do they add to or subtract from the tendency of extended extinction to diminish savings? One previous experiment using taste-aversion conditioning in rats revealed that a combined increase in the number of extinction trials and the length of the retention interval reduced recovery from extinction following US reinstatement (Schachtman, Brown, \& Miller, 1985). However, this taste-aversion experiment did not differentiate between the degree of extinction and the retention interval as the critical factor. In the present experiment, we sought to unconfound the degree of extinction and retention interval. Recall that the total retention interval between Stage 1 and Stage 3 was 20 days for all three experimental groups. If retention losses diminished apparent savings, then these losses were equated for all three experimental groups. Hence, the graded effects of extinction trials on savings were separate from any retention losses.

\section{GENERAL DISCUSSION}

The results of the present experiments provide an important demonstration of the robust nature of savings in two different classical conditioning preparations in the rabbit. Experiments 1 and 2 demonstrated that after brief acquisition and extensive extinction, reacquisition was at least as fast as, and in most cases faster than, acquisition in a rest control condition. Experiment 3 demonstrated that cross-modal acquisition after extinction was at least as fast as acquisition in a rest control. However, the combination of a handful of acquisition trials with extensive extinction seems to have located the lower boundary conditions for facilitation of cross-modal acquisition. Although cross-modal facilitation was largely eliminated in Experiment 3, another form of savings, concurrent recovery, remained robust despite the extensive extinction.

The primary aim of the present experiments was to determine the joint effect of brief acquisition and extended extinction on both reacquisition and cross-modal savings. Regarding reacquisition, recall that Ricker and Bouton (1996) found that brief acquisition followed by extensive extinction eliminated rapid reacquisition and, in fact, retarded reacquisition. This retardation was obtained when the ratio of extinction trials to initial acquisition trials was increased from approximately $2: 1$ to 11:1. The present experiments revealed that, even for ratios as high as 27:1 in the NM preparation and 20:1 in the HR preparation, it was possible to reduce the rate of reacquisition but not retard it. Regarding cross-modal acquisition, recall that Westbrook and Homewood (1982) found that a ratio as low as 3:1 eliminated savings in the acquisition of aversion to an orthogonal taste. In the present case, ratios of approximately 13:1 and 27:1 were required to eliminate facilitation in the acquisition of the NM response to an orthogonal CS.

In theoretical terms, no single existing model can explain the complete set of key findings, but some models are less promising than others. As will be discussed below, excitation/inhibition theories have the least difficulty. Models based on changes in processing of either the CS or the US also face considerable difficulties. Finally, theories based on unlearning mechanisms face the most difficulty in explaining the present results.

\section{Excitation/Inhibition Models}

Excitation/inhibition models assume that, during extinction, the excitatory connection is not lost but is merely masked by the acquisition of countervailing inhibition (Bouton, 1988; Konorski, 1967; Pavlov, 1927; Pearce \& Hall, 1980; Wagner, 1981). Early theorists (Hull, 1943, pp. 284, 300; Pavlov, 1927, pp. 68-87) postulated that inhibition was highly labile relative to excitation, and Bouton (1993) has contended that the labile nature of inhibition arises from its greater sensitivity to changes in the experimental context. ${ }^{1}$ These assumptions can provide an explanation for rapid reacquisition and concurrent recovery. In reacquisition training, pairings of the CS with the US would restore the acquisition context, for example, by reinstating the US. This change in the context between extinction and reacquisition would reduce the activation of the inhibitory association and permit the CS to activate its excitatory connection in an unimpeded fashion. By the same token, introduction of a new CS paired with the US may also largely restore the acquisition context and, hence, allow for a renewal of the original excitatory association when the old CS is tested, thus bringing about concurrent recovery.

Although excitation/inhibition theories can explain rapid reacquisition and concurrent recovery through unmasking of an existing excitatory association, it is unclear how a new, orthogonalCS would gain access to the existing association in order to produce facilitated crossmodal acquisition. One might wish to appeal to stimulus generalization between the original CS and the new CS. However, there is no evidence that NM responding generalizes across modalities, even at a subthreshold level. For example, Kehoe (1992) collated the results of several studies in which a total of 126 rabbits received initial NM training with a CS in one modality and were then given tests for generalization to a new CS in a different 
modality. Another set of 117 animals that had not received the initial training was tested as a control group. Both the trained and the control animals showed identical and negligible levels of responding to the test CS. Given the large sample size, there was more than adequate statistical power to detect any weak generalization.

Another potential problem for excitation/inhibition theories raised by the present findings is the failure to see retardation in reacquisition even for the largest ratios of extinction trials to acquisition trials. Ordinarily, retardation is considered one of the key indicators of the existence of an inhibitory association (Rescorla, 1969). However, when one considers excitation/inhibition theories, they do not require the strength of the inhibitory association to exceed that of the excitatory association. In fact, they generally predict that the two should ultimately balance each other. Hence, retardation would be expected only under rare conditions. For example, Ricker and Bouton (1996) obtained retarded reacquisition only when retraining was conducted using partial reinforcement, a condition that, they argue, diminished the change in context from extinction to acquisition, thus allowing stronger activation of the inhibitory association.

Although it is plausible that only enough inhibition is acquired to balance excitation, this assumption does make excitation/inhibition theories difficult to test in connection with savings after extinction. For example, it would be difficult to assess when the two associations come into balance. In the present results, extending extinction well after the point at which responding disappeared still had a graded effect on both reacquisition and cross-modal acquisition. It is perfectly plausible that additional inhibition was acquired after the net associative strength dropped below the response threshold. Nevertheless, it is equally clear that these assumptions, no matter how plausible each of them may be, would accumulate in a way that would make excitation/inhibition theories almost impossible to falsify.

\section{Stimulus Processing Models}

Stimulus processing theories attempt to explain savings through changes in learning rates and response thresholds. As will be detailed below, stimulus processing theories can be broken into two subtypes. In brief, one type proposes changes to CS processing in extinction, during which the CS is "tuned out" and its associability with the US is altered. The second type proposes changes in US processing resulting from the omission of an expected US.

CS processing theories. CS processing theories of classical conditioning gained currency as a result of the discovery of latent inhibition, in which preexposure to CS-alone presentations retarded CR acquisition during subsequent CS-US pairings (Lubow \& Moore, 1959). Excitation/inhibition accounts would expect initial CSalone presentations to have no effect on subsequent learning, because there would be no opportunity for excitatory and/or inhibitory associations to form during the CS-alone presentations (Mackintosh, 1975). Hence, the retardation in CR acquisition has been attributed to a reduction in the salience of the CS, which is often expressed quantitatively as a reduction in a CS-specific learning rate parameter $(\alpha)$ (Frey \& Sears, 1978; Mackintosh, 1975; Pearce \& Hall, 1980).

CS processing theories can explain the graded reduction in reacquisition seen when CS-US pairings follow extensive extinction training. Just as increasing the number of CS preexposures in the latent inhibition paradigm progressively reduces the salience of the CS (Lubow, Alek, \& Arzy, 1975; Siegel, 1969), CS processing theories would suppose that prolonged extinction training also reduces the salience of the CS even after CRs have entirely disappeared.

It should be borne in mind that, in Experiments 1 and 2 , reacquisition was never retarded as seen in latent inhibition. A similar asymmetry between reacquisition and latent inhibition has been observed by Aguado et al. (2001) in taste-aversion learning. They found that reacquisition after extinction was less retarded than latent inhibition after extensive preexposure to the CS. Aguado et al.'s findings and even the persistent rapid reacquisition seen in the present experiments are not fatal to CS processing theories. They can explain rapid reacquisition after extensive extinction in two ways. First, rapid reacquisition would occur if the CS-specific learning rate $(\alpha)$ remained elevated in comparison with its initial value in a naive control condition. Second, even if prolonged extinction training drove the value of $\alpha$ below its initial value, this reduction in $\alpha$ would also slow down any loss in excitatory associative strength and/or acquisition of inhibitory associative strength (see, e.g., Mackintosh, 1975; Pearce \& Hall, 1980). Hence, there could be a positive net value in the remaining excitatory associative strength that would be available when CS-US pairings are reintroduced and the value of $\alpha$ rises again.

CS processing theories encounter the same difficulties as do excitation/inhibition theories with respect to cross-modal savings. The CS processing theories have no explanation for transfer between orthogonal CSs. Specifically, alterations in the value of $\alpha$ for one CS would not generalize to other, distinctive CSs. Hence, CS processing theories would not predict facilitation in the rate of CR acquisition to a cross-modal CS, especially after even moderate amounts of extinction in which the value of $\alpha$ would be returned to its initial level or even lower. In the same way, concurrent recovery of CRs to the original CS cannot be readily explained by CS processing theories: During pairings of the new CS with the US, the value of $\alpha$ for the new CS would rise, but, without a mechanism for generalization of $\alpha$ values, there is no way that the value of $\alpha$ for the original, now extinguished, CS could rise to expose any residual excitatory associative strength possessed by the original CS.

US processing theories. Rescorla and Heth (1975) proposed that the magnitude and quality of a "US representation" play a substantial role in the expression of a 
CS-US association. That is, overt responding is a product of the strength of the CS-US association and the integrity of the US representation activated through the associative linkage. During extinction, the US representation is postulated to deteriorate as a result of its being activated by the CS in the absence of the US. Hence, responding could decline without either a reduction in the excitatory associative linkage or acquisition of inhibition. However, Rescorla and Heth also allowed for a loss of associative strength during extinction. Finally, Rescorla and Heth postulated that the US representation can be quickly reestablished by presentation of the US just a few times, either alone or in CS-US pairings.

This set of postulates can explain a number of the present findings, but not all of them. Rapid reacquisition can be explained easily by an appeal to the assumption that the US representation is quickly reestablished and, thus, exposes the still existing CS-US association. However, the graded effect of extended extinction in diminishing rapid reacquisition cannot be readily explained by a continuing deterioration in the US representation, given the assumed rapidity of its reestablishment. Some other mechanism, such as associative loss, would be necessary.

Cross-modal savings are equally perplexing within a US processing account that does not make additional assumptions. In particular, Rescorla and Heth's (1975) hypothesis cannot explain facilitated cross-modal acquisition, because, in the case of a new CS, there is no excitatory associative strength to be exposed by the US representation. However, Rescorla and Heth's hypothesis can explain concurrent recovery. As pairings of the new CS with the US proceed and the US representation is reestablished, concurrent recovery would be expected to occur, and in the robust fashion observed in Experiment 3. Furthermore, because the reestablishment of the US representation is presumed to be independent of the associative strength of the new CS, concurrent recovery would be expected to occur in the absence of facilitated crossmodal acquisition, as was seen in Experiment 3.

\section{Unlearning/Protection Models}

Unlearning/protection theories assume that, during extinction, excitatory associative streng th is diminished, but a central portion of that excitatory strength remains protected even though the CR has disappeared (Kehoe, 1988; Medina et al., 2001). Kehoe's (1988) connectionist model, which is shown in Figure 5, depicts CR acquisition as relying on a sequence of two associative links. During initial CS-US pairings, a stimulus-specific link develops between the CS and an intermediate, "hidden" unit (X). When this link is strong enough, an additional link develops between the $\mathrm{X}$ unit and a second unit $(\mathrm{R})$, which gives rise to the $\mathrm{CR}$ and the UR. CRs to a tone CS (T) would begin to appear once the T-X and X-R connections are both established. At the beginning of extinction, both the $\mathrm{T}-\mathrm{X}$ and the $\mathrm{X}-\mathrm{R}$ connections would start to diminish. As the T-X connection, however, becomes too weak to activate the $\mathrm{X}$ unit, the $\mathrm{X}-\mathrm{R}$ connec- tion is protected from further extinction. Consequently, a large portion of the $\mathrm{X}-\mathrm{R}$ connection is preserved. During subsequent reacquisition training, the $\mathrm{CR}$ would reappear quickly when the $\mathrm{T}-\mathrm{X}$ connection becomes strong enough to activate $X$ and, hence, to tap into the residual strength of the $\mathrm{X}-\mathrm{R}$ connection. Likewise, during subsequent training with a new $\mathrm{CS}$ - for example, a light (L) — CR acquisition would appear quickly because it requires only the establishment of a new CS-specific link (i.e., $\mathrm{L}-\mathrm{X}$ ), which then capitalizes on the existing $\mathrm{X}-\mathrm{R}$ link.

Although Kehoe's (1988) model predicts rapid reacquisition and facilitated cross-modal acquisition, it does not predict that, with extended extinction, these savings would be diminished to the point of virtual elimination, precisely because the $\mathrm{X}-\mathrm{R}$ link becomes inaccessible to further loss when the CS-specific link is unlearned. For the same reason, Kehoe's (1988) layered network cannot explain concurrent recovery, especially after extended extinction, which would eliminate the original CS-specific link. The model does not allow for generalization between CS-specific links. Hence, acquisition of a new CS-specific link would not be able to reactivate an old CS-specific link even if it had some residual excitatory value.

\section{Hybrid Models}

As may now be apparent, no single approach adequately explains the present findings. Fortunately, most of the present approaches can be integrated with each other. The key to avoiding an eclectic, untestable mess, however, is to identify a coherent, minimal number of assumptions. In an attempt to do so, we have developed a pair of models based on the now familiar Rescorla and Wagner (1972) model. (See the Appendix for all mathematical formulas used in the Rescorla-Wagner model and the models described verbally below. See Equation A1 for the basic Rescorla-Wagner rule.)

Model 1: US representation. The first model extends the core ideas inherent in Rescorla and Heth's

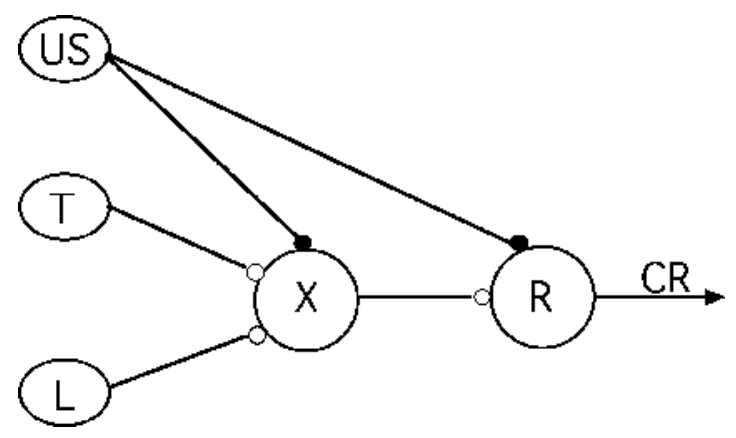

Figure 5. Kehoe's (1988) connectionist model for acquisition, extinction, and savings in classical conditioning. It contains three sensory inputs (US; tone, T; light, $L$ ) and two adaptive units (X, $R)$. There are plastic excitatory connections between the CS inputs ( $T$ and $L$ ) and the $X$ unit and between the $X$ and $R$ units. 
(1975) hypothesis of US processing. Whereas Rescorla and Heth appeared to assume that the US representation affects only the expression of associative strength, Model 1 assumes that the US representation affects both the rate of learning and its expression. To do so, the RescorlaWagner formula is supplemented by two rules that mathematically tie the notion of a US representation to the US-related learning-rate parameter $(\beta)$ : The first rule assumes that the US representation $(\beta)$ grows when there is a positive change in associative strengths and diminishes when there is a negative change in associative strengths (see Equation A2 in the Appendix). The starting value for $\beta$ is assumed to be small, and hence, there are only small increments in associative strength at the start of conditioning. The second rule assumes that the US representation plays a role in CR performance by dictating the response threshold (Equations A3 and A4). According to this rule, growth in the US representation reduces the threshold, whereas a decline in the US representation increases it.

According to Model 1, decrements in extinction reflect not only changes in associative connections, but also changes in the response threshold. At the beginning of extinction, the threshold is low, but as $\beta$ decreases, the threshold rises, and it becomes increasingly difficult for the CS to elicit the CR. In addition, changes in $\beta$ will decrease as the changes in associative strength become smaller. With continued extinction trials, both the rate of change in associative strength and, consequently, the change in $\beta$ will become progressively smaller. Consequently, a small amount of excitatory associative strength will tend to survive vast amounts of extinction, and, by the same token, $\beta$ will tend to remain elevated in comparison with its initial level.

This model can explain rapid reacquisition of an extinguished response through two complementary mechanisms. At the end of extinction, the CS's excitatory strength remains somewhat protected; thus, the CS starts with a small, subthreshold associative strength. In addition, the US learning rate parameter, $\beta$, remains elevated in comparison with its initial level, and, consequently, reacquisition will occur at a faster rate than did initial acquisition. Changes in $\beta$ could also account for facilitated cross-modal acquisition. Acquisition to a second, orthogonalCS would also proceed as a function of $\beta$ and would be rapid in comparison with a rest control. However, changes in $\beta$ would also predict that, given a sufficient number of extinction trials, the rates of reacquisition and of cross-modal acquisition would diminish, as is seen in the present experiments. (See Figure A1, panels $\mathrm{A}$ and $\mathrm{B}$, in the Appendix for simulations of reacquisition and cross-modal acquisition, respectively, as a function of the number of extinction trials.)

To a lesser extent, this model reproduces concurrent recovery. The presentation of the CS-US pairings results in an increase in $\beta$, which lowers the threshold for activation. The decrease in the threshold for activation allows for the exposure of any residual excitatory strength and recovery of responding to the original CS. However, the protection of the excitatory associative strength to the original CS is relatively small, and it is diminished with continued extinction. Hence, in its current state of development, this model does not predict the magnitude of concurrent recovery seen at the most extended extinction in Experiment 3. (See Figure A1, panel C, in the Appendix for simulations of concurrent recovery.)

In summary, through the addition of a US representation mechanism to the Rescorla-Wagner model, Model 1 was able to produce rapid reacquisition and facilitated cross-modal acquisition. The basic Rescorla-Wagner model itself could not yield either of these outcomes. Conversely, only a layered network has previously been able to explain facilitated cross-modal acquisition. Moreover, Model 1 also yielded a graded effect of the extinction/acquisition ratio on both reacquisition and cross-modal acquisition. Model 1 could produce concurrent recovery, but only at smaller extinction/acquisition ratios.

Model 2. A second model was formulated for two reasons: (1) to attempt to increase simulated concurrent recovery to more realistic levels, and (2) to implement the core ideas in Bouton and Swartzentruber's (1986) occasionsetting model of extinction and savings. According to their model, extinction occurs when the context becomes a negative occasion setter. Conversely, CRs can reappear if the context is altered either back to the original context of acquisition (reinstatement) or to a new context (renewal), both of which lack occasion-setting properties. According to Bouton (1993), the experimental context can depend on more than the physical aspects of the experimental apparatus. Context can change, for example, through reintroduction of the US or alterations in timerelated internal processes.

In our implementation (see Equation A5), extinction occurs through both a loss in the excitatory strength of the CS and the acquisition of negative occasion setting by the extinction context (Harris \& Westbrook, 1998). As extinction proceeds, the two processes will balance each other, changes in both processes will cease, and, thus, substantial excitatory strength will be protected. Most important, Model 2 attempts to reproduce concurrent recovery by assuming that changes in contextual variables between extinction and cross-modal training would allow the protected associative strength of the original CS to be expressed (see Equations A5, A6, and A7).

Simulations (see Figure A2) revealed that Model 2 produced an incremental improvement over Model 1. As was intended, Model 2 yielded greater levels of concurrent recovery under larger extinction/acquisition ratios. However, this improvement was not without cost. Simulated reacquisition and cross-modal acquisition levels after extended extinction appeared greater than those seen in the present experiments. Extensive attempts to fine-tune the parameter values of Model 2 failed to yield realistic levels of reacquisition, cross-modal acquisition, and concurrent recovery at the same time.

The notion that concurrent recovery can be explained through context-dependent mechanisms remains attrac- 
tive. However, it also remains to be seen whether the extra complexity of Model 2 will ultimately yield enough predictions to justify its retention. Alternatively, a simpler implementation of context dependency would be more likely to be fruitful. We made attempts to simplify the model by eliminating the US representation mechanisms. However, the US representation mechanisms were vital to the functioning of the model. Without them, facilitated cross-modal acquisition could not be reproduced under any conditions.

\section{REFERENCES}

Aguado, L., de Brugada, I., \& Hall, G. (2001). Tests for inhibition after extinction of a conditioned stimulus in the flavour aversion. Quarterly Journal of Experimental Psychology, 54B, 201-217.

Balaz, M. A., Gutsin, P., Cacheiro, H., \& Miller, R. R. (1982). Blocking as a retrieval failure: Reactivation of associations to a blocked stimulus. Quarterly Journal of Experimental Psychology, 34B, 99-113.

Bouton, M. E. (1986). Slow reacquisition following the extinction of conditioned suppression. Learning \& Motivation, 17, 1-15.

Bouton, M. E. (1988). Context and ambiguity in the extinction of emotional learning: Implications for exposure therapy. Behaviour Research \& Therapy, 26, 137-149.

Bouton, M. E. (1993). Context, time, and memory retrieval in the interference paradigms of Pavlovian learning. Psychological Bulletin, 114, 80-99.

Bouton, M. E., \& Nelson, J. B. (1998). The role of context in classical conditioning: Some implications for cognitive behavior therapy. In W. O'Donohue (Ed.), Learning and behavior therapy (pp. 59-84). Boston: Allyn \& Bacon.

Bouton, M. E., \& Swartzentruber, D. (1986). Analysis of the associative and occasion-setting properties of contexts participating in a Pavlovian discrimination. Journal of Experimental Psychology: Animal Behavior Processes, 12, 333-350.

BRANDON, S. E., \& Wagner, A. R. (1991). Modulation of a discrete Pavlovian conditioned reflex by a putative emotive Pavlovian conditioned stimulus. Journal of Experimental Psychology: Animal Behavior Processes, 17, 299-311.

Calton, J. L., Mitchell, K. G., \& Schachtman, T. R. (1996). Conditioned inhibition produced by extinction of a conditioned stimulus. Learning \& Motivation, 27, 335-361.

Coffin, J. M., \& Woodruff-PAK, D. S. (1993). Delay classical conditioning in young and older rabbits: Initial acquisition and retention at 12 and 18 months. Behavioral Neuroscience, 107, 63-71.

Frey, P. W., \& Sears, R. J. (1978). Model of conditioning incorporating the Rescorla-Wagner associative axiom, a dynamic attention process, and a catastrophe rule. Psychological Review, 85, 321-340.

Gormezano, I. (1966). Classical conditioning. In J. B. Sidowski (Ed.), Experimental methods and instrumentation in psychology (pp. 385420). New York: McGraw-Hill.

Gormezano, I., \& GibBs, C. M. (1988). Transduction of the rabbit's nictitating membrane response. Behavior Research Methods, Instruments, \& Computers, 20, 18-21.

Gormezano, I., Kehoe, E. J., \& Marshall, B. S. (1983). Twenty years of classical conditioning research with the rabbit. In J. M. Sprague \& A. N. Epstein (Eds.), Progress in psychobiology and physiological psychology (pp. 197-275). New York: Academic Press.

Grant, M., \& Young, D. (1971). The effects of preexposure to a learning apparatus. Behavioral Research Methods \& Instrumentation, 3, 251-252.

Harris, J. A., \& WeSt brook, R. F. (1998). Evidence that GABA transmission mediates context-specific extinction of learned fear. Psychopharmacology, 140, 105-115.

Hart, J. A., Bourne, M. J., \& Schachtman, T. R. (1995). Slow reacquisition of a conditioned taste aversion. Animal Learning \& Behavior, 23, 297-303.

Hinson, R. E. (1982). Effects of UCS preexposure on excitatory and inhibitory rabbit eyelid conditioning: An associative effect of conditioned contextual stimuli. Journal of Experimental Psychology: Animal Behavior Processes, 8, 49-61.

Holland, P. C. (1986). Transfer after serial feature positive discrimination training. Learning \& Motivation, 17, 243-268.

Holland, P. C. (1989). Transfer of negative occasion setting and conditioned inhibition across conditioned and unconditioned stimuli. Journal of Experimental Psychology: Animal Behavior Processes, 15, 311-328.

Holland, P. C. (1992). Occasion setting in Pavlovian conditioning. In D. L. Medin (Ed.), The psychology of learning and motivation (pp. 69-125). San Diego: Academic Press.

Hull, C. L. (1943). Principles of behavior. New York: Appleton-CenturyCrofts.

Kapp, B. S., Whalen, P. J., Supple, W. F., \& Pascoe, J. P. (1992). Amygdaloid contributions to conditioned arousal and sensory information processing. In J. P. Aggleton (Ed.), The amygdala: Neurobiological aspects of emotion, memory and mental dysfunction (pp. 299340). New York: Wiley-Liss.

KеноE, E. J. (1988). A layered network model of associative learning: Learning to learn and configuration. Psychological Review, 95, 411433.

KenOE, E. J. (1992). Versatility in conditioning: A layered network model. In D. S. Levine \& S. J. Levin (Eds.), Motivation, emotion and goal direction in neural networks (pp. 63-90). Hillsdale, NJ: Erlbaum.

KeHoe, E. J. (2000). Extension of the CS past the US can facilitate conditioning of the rabbit nictitating membrane response. Behavioural Processes, 50, 155-164.

Kehoe, E. J., Horne, A. J., \& Macrae, M. (1995). Learning to learn: Real-time features and a connectionist model. Adaptive Behavior, $\mathbf{3}$, 235-271.

Kehoe, E. J., \& Macrae, M. (1997). Savings in animal learning: Implications for relapse and maintenance after therapy. Behavior Therapy, 28, 141-155.

Kehoe, E. J., Morrow, L. D., \& Holt, P. E. (1984). General transfer across sensory modalities survives reductions in the original conditioned reflex in the rabbit. Animal Learning \& Behavior, 12, 129136

KoNORSKI, J. (1967). Integrative activity of the brain: An interdisciplinary approach. Chicago: University of Chicago Press.

Lennartz, R. C., \& Weinberger, N. M. (1992). Analysis of response systems in Pavlovian conditioning reveals rapidly versus slowly acquired conditioned responses: Support for two factors, implications for behavior and neurobiology. Psychobiology, 20, 93-119.

LenNartz, R. C., \& Weinberger, N. M. (1994). A comparison of nonspecific and nictitating membrane conditioned responses: Additional support for two-factor theories. Psychobiology, 22, 5-15.

Lubow, R. E., AleK, M., \& ARZY, J. (1975). Behavioral decrement following stimulus preexposure: Effects of number of preexposures, presence of a second stimulus, and interstimulus intervals in children and adults. Journal of Experimental Psychology: Animal Behavior Processes, 1, 178-188.

Lubow, R. E., \& Moore, A. U. (1959). Latent inhibition: The effect of nonreinforced preexposure to the conditioned stimulus. Journal of Comparative \& Physiological Psychology, 52, 415-419.

Mackintosh, N. J. (1975). A theory of attention: Variation in the associability of stimuli with reinforcement. Psychological Review, 82, 276-298.

Macrae, M., \& Kehoe, E. J. (1999). Savings after extinction in conditioning of the rabbit's nictitating membrane response. Psychobiology, 27, 85-94.

Maes, J. H. R., \& Vossen, J. M. H. (1993). Competition for associative strength between a punctate signal and contextual stimuli: Effect of signal preexposure versus context preexposure. Behavioural Processes, 30, 29-46.

Marlatt, G. A. (1990). Cue exposure and relapse prevention in the treatment of addictive behaviors. Addictive Behaviors, 15, 395-399.

Marshall-Goodell, B., Schreurs, B. G., \& Gormezano, I. (1982). Ruler vs. the Apple II/FIRST system analysis of analog signals in classical conditioning. Behavior Research Methods \& Instrumentation, 14, 519-525. 
McAllister, D. E., \& McAllister, W. R. (1994). Extinction and reconditioning of classically conditioned fear before and after instrumental learning: Effects of depth of fear extinction. Learning \& Motivation, 25, 339-367.

McAllister, W. R., \& McAllister, D. E. (1995). Two-factor fear theory: Implications for understanding anxiety-based clinical phenomena. In W. O'Donohue \& L. Krasner (Eds.), Theories of behavior therapy: Exploring behavior change (pp. 145-171). Washington, DC: American Psychological Association.

Medina, J. F., Garcia, K. S., \& Mauk, M. D. (2001). A mechanism for savings in the cerebellum. Journal of Neuroscience, 21, 4081-4089.

Napier, R. M., Macrae, M., \& Kehoe, E. J. (1992). Rapid reacquisition in conditioning of the rabbit's nictitating membrane response. Journal of Experimental Psychology: Animal Behavior Processes, 18, 182-192.

O'Brien, R. G., \& KAISER, M. K. (1985). MANOVA method for analyzing repeated measures designs: An extensive primer. Psychological Bulletin, 97, 316-333.

OsGood, C. E. (1953). Method and theory in experimental psychology. New York: Oxford University Press.

Pavlov, I. P. (1927). Conditioned reflexes: An investigation of the physiological activity of the cerebral cortex (G. V. Anrep, Trans.). London: Oxford University Press.

Pearce, J. M., \& Hall, G. (1980). A model for Pavlovian learning: Variations in the effectiveness of conditioned but not of unconditioned stimuli. Psychological Review, 87, 532-552.

Powell, D. A., \& LiPKIN, M. (1975). Heart rate changes accompanying differential classical conditioning of somatic response systems in the rabbit. Bulletin of the Psychonomic Society, 5, 28-30.

Rescorla, R. A. (1969). Pavlovian conditioned inhibition. Psychological Bulletin, 72, 77-94.

Rescorla, R. A., \& Heth, C. D. (1975). Reinstatement of fear to an extinguished conditioned stimulus. Journal of Experimental Psychology: Animal Behavior Processes, 1, 88-96.

Rescorla, R. A., \& WAgner, A. R. (1972). A theory of Pavlovian conditioning: Variations in the effectiveness of reinforcement and nonreinforcement. In A. H. Black \& W. F. Prokasy (Eds.), Classical conditioning II (pp. 64-99). New York: Appleton-Century-Crofts.

Revusky, S., \& Coombes, S. (1979). Reacquisition of learned taste aversions. Animal Learning \& Behavior, 7, 377-382.

Ricker, S. T., \& Bouton, M. E. (1996). Reacquisition following extinction in appetitive conditioning. Animal Learning \& Behavior, 24, 423-436.

Ross, R. T., \& Scavio, M. J., JR. (1983). Perseveration of associative strength in rabbit nictitating membrane response conditioning following ISI shifts. Animal Learning \& Behavior, 11, 435-438.

ScAndReTt, J., \& GormeZano, I. (1980). Microprocessor control and A/D data acquisition in classical conditioning. Behavior Research Methods \& Instrumentation, 12, 120-125.

Scavio, M. J., JR., \& Gormezano, I. (1974). CS intensity effects on rabbit nictitating membrane conditioning, extinction and generalization. Pavlovian Journal of Biological Sciences, 9, 25-34.

Scavio, M. J., JR., Ross, R. T., \& McLeod, L. M. (1983). Perseveration of associative strength in rabbit nictitating membrane response conditioning. Animal Learning \& Behavior, 11, 91-94.
Schachtman, T. R, Brown, A. M., \& Miller, R R (1985). Reinstatementinduced recovery of a taste- $\mathrm{LiCl}$ association following extinction. Animal Learning \& Behavior, 13, 223-227.

Schachtman, T. R., Threlkeld, R., \& Meyer, K. (2000). Retention of conditioned inhibition produced by extinction. Learning \& Motivation, 31, 283-300.

Schmajuk, N. A., Lamoureux, J. A., \& Holland, P. C. (1998). Occasion setting: A neural network approach. Psychological Review, $105,3-32$.

SCHNEIDERMAN, N. (1972). Response system divergencies in aversive classical conditioning. In A. H. Black \& W. F. Prokasy (Eds.), Classical conditioning: Current theory and research (pp. 341-376). New York: Appleton-Century-Crofts.

Schneiderman, N., McCabe, P. M., Haselton, J. R., Ellenberger, H. H., Jarrell, T. W., \& Gentile, C. G. (1987). Neurobiological bases of conditioned bradycardia in rabbits. In I. Gormezano, W. F. Prokasy, \& R. F. Thompson (Eds.), Classical conditioning (pp. 3763). Hillsdale, NJ: Erlbaum.

Schneiderman, N., Smith, M. C., Smith, A. C., \& Gormezano, I. (1966). Heart rate classical conditioning in rabbits. Psychonomic Science, 6, 241-242.

Schreurs, B. G. (1993). Long-term memory and extinction of the classically conditioned rabbit nictitating membrane response. Learning \& Motivation, 24, 293-302.

SCHREURS, B. G. (1998). Long-term memory and extinction of rabbit nictitating membrane trace conditioning. Learning \& Motivation, 29, 6882.

Schreurs, B. G., \& Kehoe, E. J. (1987). Cross-modal transfer as a function of initial training level in classical conditioning with the rabbit. Animal Learning \& Behavior, 15, 47-54.

Shiffman, S., Paty, J. A., Gnys, M., Kassel, J. A., \& Hickcox, M. (1996). First lapse to smoking: Within-subject analysis of real-time reports. Journal of Consulting \& Clinical Psychology, 64, 366-379.

SIEGEL, S. (1969). Effect of CS habituation on eyelid conditioning. Journal of Comparative \& Physiological Psychology, 68, 245-248.

Smith, M., \& Gormezano, I. (1965). Effects of alternating classical conditioning and extinction sessions on the conditioned nictitating membrane response of the rabbit. Psychonomic Science, 3, 91-92.

WAGNER, A. R. (1981). SOP: A model of automatic memory processing in animal behavior. In N. E. Spear \& R. R. Miller (Eds.), Information processing in animals: Memory mechanisms (pp. 5-47). Hillsdale, NJ: Erlbaum.

Weidemann, G., \& Kehoe, E. J. (1997). Transfer and counterconditioning of conditional control in the rabbit nictitating membrane response. Quarterly Journal of Experimental Psychology, 50B, 295-316.

Westbrook, R. F., \& Homewood, J. (1982). The effect of a flavour toxicosis pairing upon long-delay, flavour aversion learning. Quarterly Journal of Experimental Psychology, 34B, 139-149.

\section{NOTE}

1. Inhibition has traditionally been viewed as a negatively valenced association acquired directly by the CS. However, inhibitory control could entail the acquisition of negative occasion setting by contextual cues (Bouton \& Swartzentruber, 1986). 


\section{APPENDIX \\ Hybrid Models of Savings: \\ Basic Rescorla-Wagner Model}

The Rescorla-Wagner model assumes that the associative strength of the $i$ th stimulus $\left(\Delta V_{i}\right)$ changes in the following fashion:

$$
\Delta V_{i}=\alpha_{i} \beta\left(\lambda ?-V_{\text {total }}\right) x_{i},
$$

where

$\alpha$ is a direct function of the salience of the $i$ th stimulus $(0<\alpha<1)$,

$\beta$ is related to the salience of the US $(0<\beta<1)$,

$\lambda$ is the total associative strength that can be supported by the US on any given trial,

$V_{\text {total }}=\sum V_{i} x_{i}$, which is the net sum of the associative strengths of active stimuli, and

$x_{i}$ is a binary variable $(1,0)$ for the presence or absence of the $i$ th stimulus.

\section{MODEL 1}

\section{US Representation}

\section{Changes in US Salience}

$$
\Delta \beta=S \cdot \Sigma \Delta V_{\text {total }} \cdot(1-\beta),
$$

where

$\Delta \beta$ is the change in the US-dependent learning rate parameter on trial $n$,

$S$ is a direct function of the physical properties of the US $(0<S<1)$,

$\sum \Delta V_{\text {total }}=\sum \Delta V_{i} x_{i}$, which is the net sum of the changes in the associative strengths of all stimuli present on the previous trial $(n-1)$, and

$(1-\beta)$ prevents $\beta$ from assuming values greater than 1 .

\section{$\beta$-Dependent Threshold}

The performance process entails two formulas: Equation A3 relates the threshold for responding to $\beta$ :

$$
\theta_{n}=\theta_{1}-\left(\beta_{n}-\beta_{1}\right)
$$

where

$\theta_{n}$ is the threshold for responding on trial $n\left(\theta_{n}>0\right)$,

$\theta_{1}$ is the initial value of the threshold,

$\beta_{n}$ is the current value of the US-dependent $\operatorname{parameter}(\beta)$, and

$\beta_{1}$ is the initial value of the US-dependent parameter $(\beta)$.

Equation A4 relates overt responding to the threshold and associative strengths:

$$
\begin{aligned}
& \text { if } \sum V_{i} x_{i}>\theta, \\
& \text { then performance }=\left(\sum V_{i} x_{i}-\theta\right) \cdot[1 /(1-\theta)], \\
& \text { otherwise } 0 \text {. }
\end{aligned}
$$

Using this formula, performance will vary between 0 and 1 , without imposing artificial boundaries.

\section{Model 1 Simulations}

Figure A1 shows simulations of Model 1 aimed at reproducing the findings of Experiments 1 and 3. The parameter values were set as follows: $\alpha_{i}=.5, \beta_{1}=.01, S=.5, \theta_{1}=.35, \lambda=1$. Panel A shows simulated reacquisition curves for three groups with differing ratios of extinction/acquisition trials plus a curve for a rest control group. In the simulation runs, there were 20 acquisition "trials," which yielded a level of $60 \%$ CRs. This initial acquisition was followed by 100, 200, or 400 extinction "trials." As can be seen, increasing ratios produced a graded reduction in the rate of reacquisition. Rapid reacquisition largely disappeared when the ratio was 20:1, similar to what was seen in Experiment 1.

Panel B of Figure A1 shows the learning curves for simulated cross-modal acquisition. As was seen in Experiment 3 as opposed to Experiment 1, facilitation of cross-modal acquisition was weaker than reacquisition (see also Macrae \& Kehoe, 1999, for direct comparisons). Nevertheless, a graded effect of the ratio of extinction/acquisition trials could still be discerned.

Finally, panel C of Figure A1 depicts the simulated level of concurrent recovery obtained under the parameters used for cross-modal acquisition. Only a tiny amount of concurrent recovery was apparent. Supplementary simulations revealed that much greater concurrent recovery could be obtained. Specifically, simulated levels up to $25 \%$ CRs occurred, but at the expense of requiring more acquisition trials and fewer extinction trials in a 1:1 ratio.

\section{MODEL 2}

\section{Contextual Modulation}

Model 2 builds on the assumptions and equations of Model 1 , specifically by assuming that the context during extinction (EC) can come to modulate responding to the CS. Changes in the modulating ability of the extinction context $\left(\Delta M_{\mathrm{EC}}\right)$ follow a Hebb-like rule:

$$
\Delta M_{\mathrm{EC}}=S_{c} \cdot(\lambda-1) \cdot\left(\sum V_{i} x_{i}+M_{\mathrm{EC}}\right) \cdot \sum V_{i} x_{i},
$$

where

$S_{c}$ is a learning rate parameter for the context $(0<S<1)$,

$\lambda$ is a binary variable $(1,0)$ for the presence or absence of the US, and

$M_{\mathrm{EC}}$ is the modulating strength of the extinction context on the previous trial $(n-1)$.

The external and internal factors that could influence the similarity of the context in Stage 3 to that of Stage 2 are grouped into a variable labeled as $P_{\mathrm{EC}}$, which stands for the parity of the Stage 3 context with the EC. Thus, the total associative strength present on any particular trial becomes

$$
V_{\text {total }}=\Sigma V_{i} x_{i}+\left(M_{\mathrm{EC}} \cdot P_{\mathrm{EC}}\right) \text {. }
$$

In cases in which the context is altered, the value of $P_{\mathrm{EC}}$ could decrease toward zero. Thus, $M_{\mathrm{EC}}$ would not be activated, and renewal of responding would occur. Similarly, if reintroduction of the US alters the animal's internal context, then $P_{\mathrm{EC}}$ could also decrease toward zero and yield reinstatement of responding. Changes in $P_{\mathrm{EC}}$ were represented as

$$
\Delta P_{\mathrm{EC}}=\mathrm{K} \cdot \Sigma V_{i} x_{i} \cdot M_{\mathrm{EC}} .
$$

Consideration of this formula reveals that, during initial acquisition training, $P_{\mathrm{EC}}$ would not change, because $M_{\mathrm{EC}}$ would remain at zero while the excitatory strength of the CS is grow- 


\section{APPENDIX (Continued)}

ing. However, during extinction training, $P_{\mathrm{EC}}$ would grow as a product of the decreases in excitatory strength and the growing inhibitory strength of the context. Finally, in reacquisition training, $P_{\mathrm{EC}}$ would decline as the residual excitatory strength of the $\mathrm{CS}$ grows in the presence of inhibition. Over reacquisition trials, the reduced value of $P_{\mathrm{EC}}$ would reduce activation of $M_{\mathrm{EC}}$, thus allowing for progressively greater expression of the excitatory strength of the CS, as seen in concurrent recovery.

Figure A2 shows simulations resulting from Model 2. This model's parameter values were the same as those used for Model 1, and its additional parameters were set as follows: $S_{c}=$ $1, K=5$. As can be seen in panels A and B of Figure A2, a

\section{(A) Reacquisition}

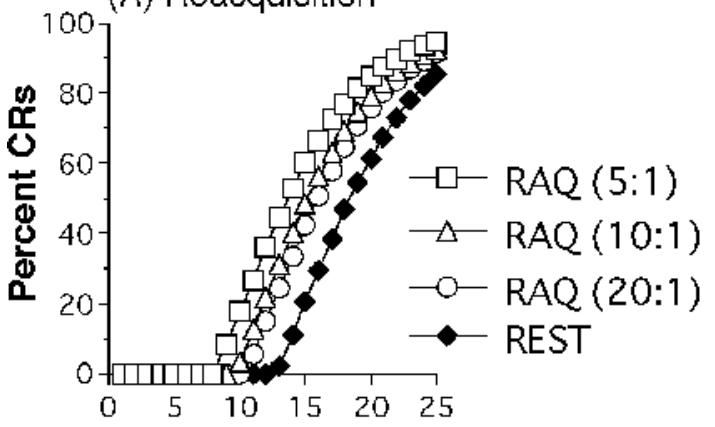

(B) Cross-Modal Acquisition
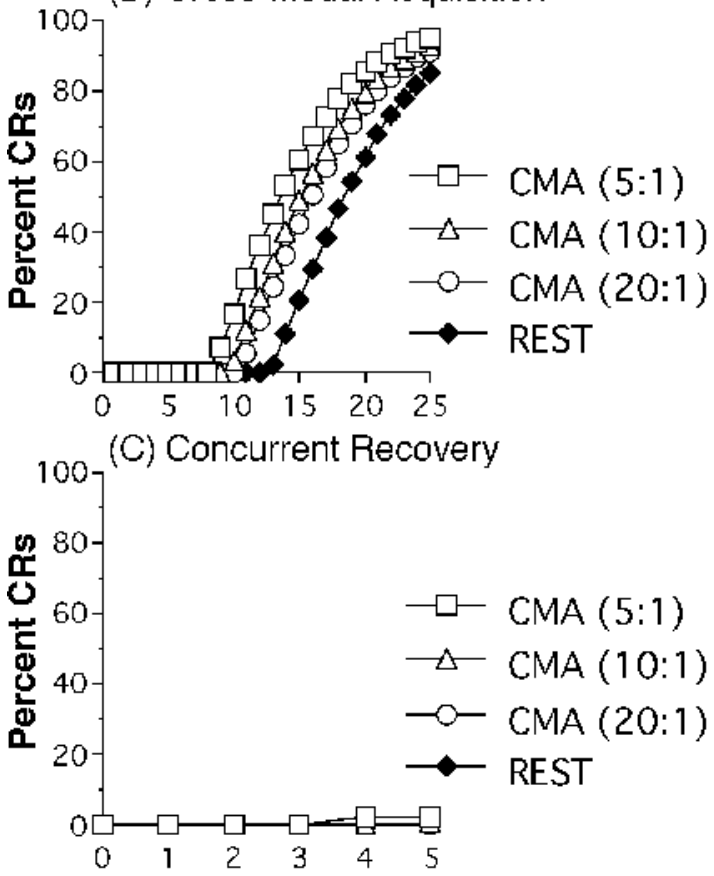

Figure A1. Simulation of reacquisition, cross-modal acquisition, and concurrent recovery by Model 1 . Panel A shows CR reacquisition after 5:1,10:1, and $20: 1$ ratios of extinction trials to initial acquisition trials, in comparison with acquisition in a rest control group. Panel B shows CR acquisition to an orthogonal CS after 5:1, 10:1, and 20:1 ratios of extinction trials to initial acquisition trials in comparison with acquisition in a rest control group. Panel $\mathrm{C}$ shows responding to the original CS during acquisition of responding to an orthogonal CS. strong graded effect of extinction/acquisition ratios appeared for both reacquisition and cross-modal acquisition. In the case of cross-modal acquisition, the overall facilitation was stronger than that seen in Model 1 or the actual experimental results. At the same time, however, an inspection of panel $\mathrm{C}$ reveals that concurrent recovery was very much greater than that obtained under the same conditions in the simulations for Model 1. There was, however, a graded effect of extinction/acquisition ratios on concurrent recovery that was not apparent in the experimental results. Supplementary simulations revealed that concurrent recovery could be further increased and graded effects erased if the parity of the extinction context, $P_{\mathrm{EC}}$, was set

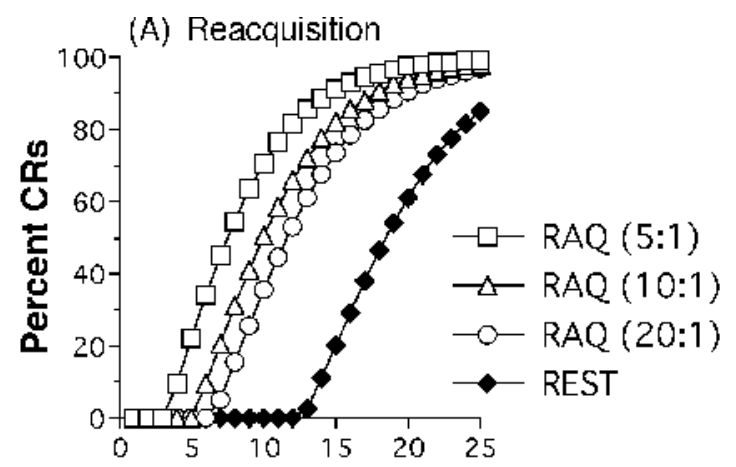

(B) Cross-Modal Acquisition
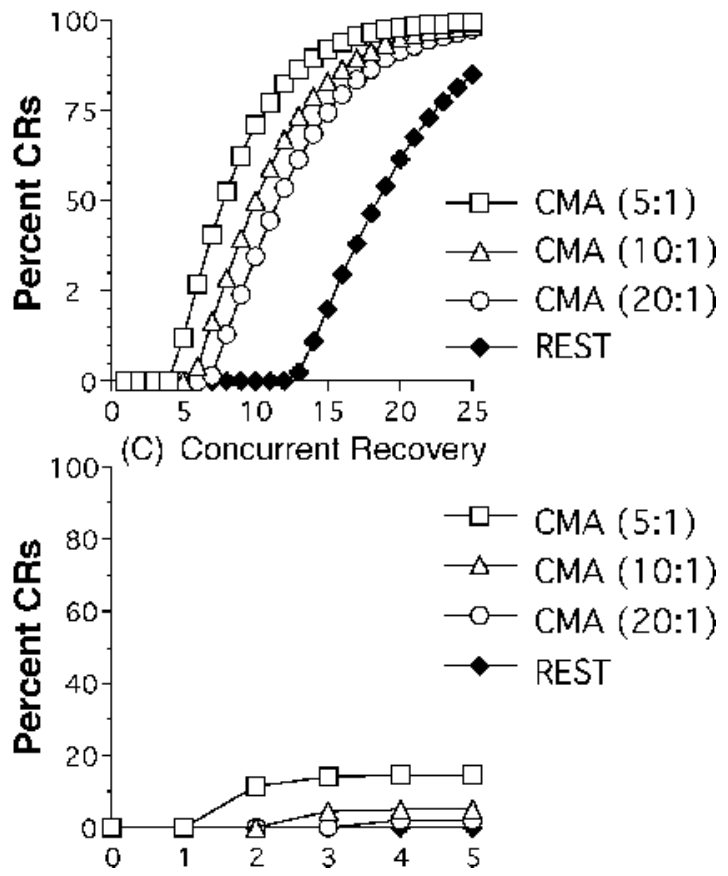

Figure A2. Simulation of reacquisition, cross-modal acquisition, and concurrent recovery by Model 2 . Panel A shows CR reacquisition after 5:1,10:1, and 20:1 ratios of extinction trials to initial acquisition trials, in comparison with acquisition in a rest control group. Panel B shows CR acquisition to an orthogonal CS after 5:1, 10:1, and 20:1 ratios of extinction trials to initial acquisition trials in comparison with acquisition in a rest control group. Panel $\mathrm{C}$ shows responding to the original CS during acquisition of responding to an orthogonal CS. 


\section{APPENDIX (Continued)}

to 1 during Stage 2 extinction and to 0 during Stage 3 training, thus unmasking all the residual excitatory strength of the CS. However, this assumption that the extinction context is entirely lost during Stage 3 training also eliminated the graded effect of extinction/acquisition ratios on rapid reacquisition and crossmodal acquisition.

The addition of a mechanism for contextual control $\left(M_{\mathrm{EC}}\right.$, $\left.P_{\mathrm{EC}}\right)$ confers considerable flexibility on the model to accommodate differences across response systems and species in the results of extinction. At present, the parameters of these terms are set to allow very broad transfer of the contextual modulation, as has been seen in the rabbit (Brandon \& Wagner, 1991; Weidemann \& Kehoe, 1997). However, where there is a lack of transfer (e.g., Holland, 1986, 1989, 1992), the $P_{\text {EC }}$ term could be reduced as a result of a configural interaction between the contextual stimuli and the test CS (Schmajuk, Lamoureux, \&
Holland, 1998). Other contextual manipulations, such as reintroduction of the US after extinction(reinstatement)and the use of unpaired US presentations during extinction, could also be accommodated by the contextual variables in addition to the US representation process contained in both models. However, for purposes of modeling the present results, the US representation process is sufficient inasmuch as the rabbit NM preparation has shown neither discernible reinstatement effects nor effects of unpaired USs in extinction (Napier et al., 1992).

Even with the contextual control mechanism, the present model does not have unlimited scope. Like the basic RescorlaWagner model, it cannot ex plain CS processing effects, such as latent inhibition and perhaps slow reacquisition. It would be necessary to add mechanisms for adjusting the CS-related learning parameter as, for example, Frey and Sears (1978) have done using the Rescorla-Wagner model.

(Manuscript received May 2, 2002;

revision accepted for publication September 12, 2002.) 